\title{
Broad Cross-National Public Support for Accelerated COVID-19 Vaccine Trial Designs
}

\author{
David Broockman* Joshua Kalla $^{\dagger} \quad$ Alexander Guerrero ${ }^{\ddagger}$ \\ Mark Budolfson $^{\S} \quad$ Nir Eyal $^{\Uparrow}$ Nicholas P. Jewell॥ Monica Magalhaes** \\ Jasjeet S. Sekhon ${ }^{\dagger \dagger}$
}

December 2, 2020

\begin{abstract}
A vaccine for COVID-19 is urgently needed. Several vaccine trial designs may significantly accelerate vaccine testing and approval, but also increase risks to human subjects. Concerns about whether the public would see such designs as ethical represent an important roadblock to their implementation; accordingly, both the World Health Organization and numerous scholars have called for consulting the public regarding them. We answered these calls by conducting a cross-national survey $(n=5,920)$ in Australia, Canada, Hong Kong, New Zealand, South Africa, Singapore, the United Kingdom, and the United States. The survey explained key differences between traditional vaccine trials and two accelerated designs: a challenge trial or a trial integrating a Phase II safety and immunogenicity trial into a larger Phase III efficacy trial. Respondents' answers to comprehension questions indicate that they largely understood the key differences and ethical trade-offs between the designs from our descriptions. We asked respondents whether they would prefer scientists to conduct traditional trials or one of these two accelerated designs. We found broad majorities prefer for scientists to conduct challenge trials (75\%) and integrated trials (63\%) over standard trials. Even as respondents acknowledged the risks, they perceived both accelerated trials as similarly ethical to standard trial designs. This high support is consistent across every geography and demographic subgroup we examined, including vulnerable populations. These findings may help assuage some of the concerns surrounding accelerated designs.
\end{abstract}

Keywords: COVID-19; vaccine ethics; challenge trials; public opinion

${ }^{*}$ Department of Political Science, University of California, Berkeley.

${ }^{\dagger}$ To whom correspondence should be addressed: josh.kalla@yale.edu. Department of Political Science and Department of Statistics \& Data Science, Yale University.

${ }^{\ddagger}$ Department of Philosophy, Rutgers University.

${ }^{\S}$ Department of Philosophy, University of Vermont.

${ }^{\top}$ Center for Population-Level Bioethics, Rutgers University.

"London School of Hygiene \& Tropical Medicine and Division of Biostatistics, School of Public Health, University of California, Berkeley.

${ }^{* *}$ Center for Population-Level Bioethics, Rutgers University.

${ }^{\dagger \dagger}$ Department of Statistics \& Data Science and Department of Political Science, Yale University. 


\section{Introduction}

2 Each week without a COVID-19 vaccine exacts an unimaginable toll on global public health, economic livelihoods, and political stability [1]. At present, well over 100 COVID-19 vaccine candidates have been identified, at least 23 of which are in clinical trials worldwide [2]. Traditional efficacy trial designs take many months and rely on the persistence of high transmission rates around the trial site. However, several trial design options may expedite the process. Two of the leading options are, first, the use of "human challenge studies," wherein study participants volunteer to be exposed to the virus instead of having scientists wait for participants to be exposed to it in their daily lives (potentially accompanied by additional safety testing in a diverse

population) [3]; and, second, the integration of smaller Phase II safety and immunogenicity trials into larger Phase III efficacy trials, wherein more study participants receive a vaccine candidate before data about its safety and immunogenicity are available from a traditional Phase II trial. These approaches may significantly accelerate COVID-19 vaccine development [3-

7]. However, they also create risks to participants: in the case of challenge trials, deliberately exposing participants to the virus; and, in the case of integrated trials, exposing additional participants to a vaccine before Phase II safety and immunogenicity studies have been completed.

While technical questions also surround the use of these and related approaches in COVID19 vaccine testing [8-11], several of the roadblocks to their implementation depend in part on the answer to an empirical question: would members of the general public see these designs as ethical [12-16]?

To understand how members of the public informed of the ethical trade-offs involved would view these questions, we measured public opinion on the ethics of accelerated vaccine trial designs.

There are at least three reasons why public opinion towards the ethics of these designs is 
relevant to vaccine trialists, ethicists, and policymakers.

First, there has been considerable debate about the ethics of accelerated designs for COVID19 vaccine trials, particularly human challenge trials $[3,8,13-18]$. Ethicists have held that part of what determines whether proposed research is ethical are societal attitudes toward that research, especially among those individuals and communities who will be most affected by it [19]. This is one reason that community members have long been included on institutional research ethics committees [20]. Decisions about whether to use standard or accelerated COVID19 vaccine trial designs affect people worldwide. Accordingly, the WHO recently identified "consultation and engagement with the public" as a core criterion for the ethical acceptability of challenge trials [12]. "Community engagement" is said to be an important ethical safeguard "to ... ensure that the research is consistent with the community's values, show respect for members of the community, and enhance transparency" [19]. Notable scholars have also explicitly called for "public opinion surveys [to] identify concerns" on the ethics of COVID-19 challenge trials [13] and "public engagement" to "assess the local acceptability of human challenge studies" [16]. Our research answers these calls.

Second, vaccines are only effective if the public gets vaccinated, and public trust in vaccines may depend in part on public views about the ethics of the process by which those vaccines were developed and tested [21]. As a result, some scholars have expressed concern that the use of human challenge trials could "feed distrust among the public," and therefore "exacerbate challenges in vaccine roll-out and delay uptake of an effective vaccine" [22]. Our research can help empirically assess such concerns.

Third, as many decisions about vaccine trials and vaccine manufacturing will be made by government officials who are accountable to public opinion, it is important to know what the public thinks about the social and ethical trade-offs these options involve [23]. In practice, policymakers and regulators may be hesitant to support an accelerated design viewed as unethical 
by the public.

However, despite a plethora of research on public opinion regarding medical research [23] and on how individuals make ethical judgments [24], relatively little is known about how individuals perceive the ethics of accelerated vaccine trials on consenting volunteers, especially in the setting of the current global public health emergency. One exception is Gbesemete et al., who find strong public support for COVID-19 challenge trials in focus groups conducted with 57 young people in the United Kingdom [25]. Our work, described below, builds on their work with a larger sample size, cross-national data, a more diverse subject pool, and a different, complementary research design.

\section{Materials and Methods}

To measure public opinion about COVID-19 vaccine testing, we surveyed people worldwide in May 2020. We recruited participants to the survey using the online sample provider Lucid. Prior research shows that US Lucid respondents demographically track well with US national benchmarks and that many political, psychological, and experimental results replicate on Lucid samples [26]. In addition to surveying $n=2,180$ individuals in the United States, we also surveyed approximately 500 individuals through Lucid in each of the following predominantly English-speaking geographies worldwide: Australia $(n=500)$, Canada $(n=687)$, Hong Kong ( $n=422)$, New Zealand $(n=498)$, South Africa $(n=548)$, Singapore $(n=520)$, the United Kingdom $(n=565)$. Survey respondents in Australia, the United Kingdom, and the United States surveys were selected to match Census population benchmarks on age, gender, and race and ethnicity, but this was not possible in the other geographies. Although the results are not meaningfully different across geographies, respondents in Canada, Hong Kong, New Zealand, South Africa, and Singapore were not selected to match Census benchmarks and the results for these geographies should be viewed with this limitation in mind. Furthermore, prior work 
on the representativeness of Lucid has been limited to the US. All surveys were conducted in English. The Supplementary Materials provides further detail on the demographics of survey respondents. Later, we also report results from sensitivity analyses and placebo tests to further support the robustness of our findings.

Survey respondents were randomly assigned to participate in one of two studies. Study 1 asked respondents about a standard Phase III trial in which scientists wait for participants to be exposed to the virus in the real world and a challenge trial in which participants are intentionally exposed to the virus. Study 2 asked respondents about a standard Phase II followed by Phase III trial and an integrated Phase II and III trial in which the Phase II safety and immunogenicity trial is integrated into a larger Phase III efficacy trial, thereby reducing the vaccine testing timeline. ${ }^{1}$

In both studies, we described essential details of these research designs for respondentsincluding their procedures, risks to participants, and benefits to society. Figure 1 provides an example description of the designs that we showed participants in Study 1 (see Figure S4 for the stimulus used for the integrated trial). We followed these descriptions with a bulleted summary of the key differences (given in the Supplementary Materials).

In both studies, we randomly assigned each respondent to several parameters of the vaccine trials we described, including their sample sizes, COVID-19 infection and death rates for their participants, the vaccine approval timeline under standard trials, and how much alternative designs would accelerate this timeline. These randomizations were intended to evaluate the robustness of our findings to a range of assumptions about the likely design and consequences of vaccine trials given the uncertainty surrounding all of these parameters. The Supplementary Materials provides the full wording of the scenarios.

\footnotetext{
${ }^{1}$ We asked respondents about an integrated design that involved giving additional participants a potentially ineffective or unsafe vaccine before its lack of effectiveness or safety was detected. However, adaptive trial designs exist that would likely result in even fewer participants being exposed than in standard designs, including designs that adaptively learn optimal dosage [6]. Based on our results, it seems unlikely that public opinion would be less friendly to a trial design that was both accelerated and involved lower risk to study participants.
} 
There is ongoing scientific uncertainty and differences of opinion regarding the likely design, benefits, and risks of both conventional and accelerated COVID-19 vaccine trial designs. This ongoing uncertainty merits several comments about our summaries of the designs for respondents. First, our summaries should not be interpreted as making any new scientific claim about the likely trial designs; rather, they represented our best assessment of the available evidence as of when the survey was conducted (May 2020). Second, reflecting the scientific uncertainty about likely trial designs, as described above we also randomized a number of aspects of the scenarios (as shown in Figure 1 and detailed in the Supplementary Materials). As we show below, our results are robust across these potential trial design details. Third we did not include any scenarios in which accelerated designs took as long or longer than conventional designs, as the ethical case for accelerated designs is mainly relevant if they in fact do accelerate vaccine approval timelines (which is a separate question). Finally, our challenge trial scenarios always described it as "very unlikely any study participants would die of coronavirus" based on the available research about the infection fatality rate for young, healthy people, who we state would form the subject pool for a challenge trial [12, 16, 27, 28], $\lrcorner^{2}$

After presenting the study designs, we asked respondents which of the two trials they would prefer to see scientists conduct. We next asked respondents to rate how ethical and how scientifically valid they considered each trial design and how likely they would be to take the vaccine if it had been tested using each design, if the vaccine were to be approved. We also asked several questions to measure respondents' successful comprehension of the study designs; this allows us to determine whether our survey instrument successfully communicated the intended differences between the vaccine trial designs. We ended the survey with several demographic questions, which allow us to identify and separately analyze data for numerous sub-populations,

\footnotetext{
${ }^{2}$ In the largest challenge trial shown to participants $(N=200)$, under a high-end estimate of the infection fatality rate for young people in the available research of $0.03 \%$, the probability that zero participants of 100 in the placebo condition infected with SARS-CoV-2 would die is $(1-0.0003)^{100}=97.0 \%$.
} 
Figure 1: Example Stimulus, Study 1 (Study A is the Challenge Trial in this Example)

\begin{tabular}{|c|c|c|c|}
\hline Name & Study A & Study B & Key Differences \\
\hline $\begin{array}{c}\text { Study } \\
\text { procedures }\end{array}$ & $\begin{array}{l}\text { 1. Recruit } 80 \text { healthy volunteers aged } 18 \text { - } \\
30 \text { to participate. } \\
\text { 2. Give } 40 \text { people the vaccine and another } \\
40 \text { people a placebo. } \\
\text { 3. Scientists expose all } 80 \text { participants to } \\
\text { the coronavirus. Scientists keep these } \\
\text { participants in a medical research center } \\
\text { where they cannot infect others, are } \\
\text { closely monitored, and provided any } \\
\text { necessary medical care. } \\
4 \text {. Scientists monitor participants for } \\
\text { several weeks to learn if the vaccine } \\
\text { works. }\end{array}$ & $\begin{array}{l}\text { 1. Recruit } 9,000 \text { healthy } \\
\text { volunteers to participate. } \\
\text { 2. Give } 4,500 \text { people the vaccine } \\
\text { and another } 4,500 \text { people a } \\
\text { placebo. } \\
\text { 3. All participants then go about } \\
\text { their daily lives. Scientists } \\
\text { monitor participants for several } \\
\text { months to learn if the vaccine } \\
\text { works. }\end{array}$ & $\begin{array}{l}\text { - In Study B, people } \\
\text { catch the coronavirus } \\
\text { on their own as they go } \\
\text { about their daily } \\
\text { lives. In Study A, } \\
\text { participants are } \\
\text { intentionally exposed to } \\
\text { the virus. }\end{array}$ \\
\hline $\begin{array}{c}\text { Risks to } \\
\text { study } \\
\text { participants }\end{array}$ & $\begin{array}{l}\text { - } 40 \text { participants in the placebo group are } \\
\text { intentionally exposed to coronavirus } \\
\text { while quarantined in a medical research } \\
\text { center. Because all participants in this } \\
\text { study are young people, it is unlikely any } \\
\text { would develop serious complications. In } \\
\text { addition, participants would likely } \\
\text { develop immunity, so are unlikely to get } \\
\text { coronavirus again or pass it along to } \\
\text { others. } \\
\text { - } 40 \text { participants who received the vaccine } \\
\text { are also intentionally exposed to } \\
\text { coronavirus. If the vaccine in the } \\
\text { study does not work, they would also get } \\
\text { coronavirus. In the worst-case scenario, } \\
\text { they could get an especially bad case of it. } \\
\text { - It is very unlikely any study participants } \\
\text { would die of coronavirus. }\end{array}$ & $\begin{array}{l}\text { - } 90 \text { participants in the placebo } \\
\text { group are expected to get } \\
\text { coronavirus from their daily lives. } \\
\text { - It is likely } 1 \text { participant would } \\
\text { die of coronavirus. } \\
\text { - If the vaccine in the study does } \\
\text { not work, } 90 \text { participants who } \\
\text { received the vaccine would also } \\
\text { get coronavirus. In the worst-case } \\
\text { scenario, they could get an } \\
\text { especially bad case of it. }\end{array}$ & $\begin{array}{l}\text { If the vaccine works: } \\
\text { - } 50 \text { more volunteers } \\
\text { catch the coronavirus in } \\
\text { Study B. } \\
\text { - } 1 \text { more volunteer } \\
\text { would die in Study B. }\end{array}$ \\
\hline $\begin{array}{l}\text { Expected } \\
\text { time until } \\
\text { vaccine } \\
\text { ready }\end{array}$ & $\begin{array}{l}\text { If the vaccine works, it would start being } \\
\text { distributed widely in } 6 \text { months from } \\
\text { today, November } 2020 \text {. }\end{array}$ & $\begin{array}{l}\text { If the vaccine works, it would } \\
\text { start being distributed widely in } \\
12 \text { months from today, May } 2021 \text {. }\end{array}$ & $\begin{array}{l}\text { - If the vaccine works, } \\
\text { Study A would allow it } \\
\text { to be ready } 6 \text { months } \\
\text { sooner than Study B. }\end{array}$ \\
\hline $\begin{array}{l}\text { Benefits to } \\
\text { society, if } \\
\text { the vaccine } \\
\text { works }\end{array}$ & $\begin{array}{l}\text { During the } 6 \text { months between now and } \\
\text { when the vaccine is ready, it is estimated } \\
\text { that: } \\
\text { - } 1,200,000 \text { people will die from } \\
\text { coronavirus. } \\
\text { - Millions of people will remain out of } \\
\text { work. } \\
\text { However, once the vaccine is ready and } \\
\text { starts reaching all those who need it in } \\
\text { November } 2020 \text { : } \\
\text { - Very few people will die of coronavirus } \\
\text { any more. } \\
\text { - Daily life and the economy will return } \\
\text { to normal. }\end{array}$ & $\begin{array}{l}\text { During the } 12 \text { months between } \\
\text { now and when the vaccine is } \\
\text { ready, it is estimated that: } \\
\text { - } 2,400,000 \text { people will die from } \\
\text { coronavirus. } \\
\text { - Millions of people will remain } \\
\text { out of work. } \\
\text { However, once the vaccine is } \\
\text { ready and starts reaching all those } \\
\text { who need it in May } 2021 \text { : } \\
\text { - Very few people will die of } \\
\text { coronavirus any more. } \\
\text { - Daily life and the economy will } \\
\text { return to normal. }\end{array}$ & $\begin{array}{l}\text { - With Study A, } \\
1,200,000 \text { lives are } \\
\text { saved. } \\
\text { - With Study A, people } \\
\text { can return to work and } \\
\text { daily life can return to } \\
\text { normal } 6 \text { months } \\
\text { sooner. }\end{array}$ \\
\hline
\end{tabular}

Note: In order to communicate the details and differences between standard and challenge trials, participants in Study 1 were shown a table like the one above. The highlighted elements were randomized across possible values detailed in the Supplementary Materials. The highlights did not appear for respondents. We randomized these parameters given uncertainty about how particular vaccine trials might be conducted, to ensure our findings were not sensitive to any of these parameters. We did not allow participants to move on from the page describing the trial design until at least 60 seconds had gone by. See the Supplementary Materials for an example from Study 2. As we show in the Supplementary Materials (Tables S2 and S6), the vast majority of survey respondents were able to correctly comprehend the key differences between the designs. 
including vulnerable sub-populations. We also use these demographic questions to construct weights for the US sample, allowing us to test whether our conclusions change when weighting our sample to the demographics of the US population. The Supplementary Materials provides the full question wording.

We pre-registered a pre-analysis plan, provided in the Supplementary Materials, that details the pre-specified analyses we planned to conduct, including which subgroups we would examine. The Supplementary Materials also details two minor deviations from our pre-analysis plan.

The survey was approved by the Committee for the Protection of Human Subjects at the University of California, Berkeley (\#2020-04-13250) and Yale University (\#20000281000). In the survey, we first asked for informed consent to participate. 471 participants did not consent and were removed from the survey.

All of the individual participant data collected during the study, after de-identification, study protocol, pre-analysis plan, informed consent form, and analytic code will be available immediately following publication with no end date to anyone who wishes to access the data for any purpose. Data will be made available indefinitely at https://osf . io/bgxe4/.

All authors declare no competing interests.

\section{Results}

First, we find that a majority of respondents successfully understood the studies we described, as most correctly answered each of several scenario comprehension questions. For example, in Study 1, 84\% (95\% CI: 82-85\%) of respondents correctly stated that the challenge trial involves intentionally infecting study participants with the virus. Similarly, 75\% (95\% CI: $73-76 \%$ ) of respondents in Study 2 correctly stated that the standard trial involves additional safety testing not present in the integrated design. Results for additional scenario comprehension questions 
are presented in the Tables S2 and S6.

We pre-specified that our primary outcome of interest was participants' answer to the question "If you had to choose, which study would you rather have scientists conduct?" Respondents had the choice of selecting "Study A" or "Study B." Whether the accelerated design was labeled as Study A or B was randomly assigned for each respondent.

Figure 2 shows our main results for this primary outcome. Overall, we find broad crossnational support for both the challenge trial and the integrated trial over standard vaccine trials. There are also similar, high levels of support in every subgroup we examined, including among vulnerable populations (e.g., those over 65 , essential workers, racial minorities), politically relevant subgroups in the United States, those without a college degree, and among those who correctly answered all scenario comprehension questions asked after the scenario was presented (see also Tables S4 and S8).

These results are robust across the various trial design assumptions we randomized to each respondent (e.g., the sample size of each trial we described). Further evidence is presented in the Supplementary Materials. Of particular interest is that the results are not particularly sensitive to the amount of time by which we tell respondents the design could accelerate vaccine development: we find similar results across the range of 2-6 months (see Tables S5 and S9). The results are also robust when the sample from the United States is weighted to match Census targets for gender, race, age, and education (see Tables S3 and S7). Supporting the breadth of public support for accelerating trial designs, multivariate regressions reveal few substantively or statistically significant demographic or attitudinal predictors of support (see Figures S2 and S4).

We present further results in the Supplementary Materials for our three secondary outcomes. In Study 1, participants stated that they saw the challenge trial as slightly more likely to be ethical ( $p<0.01$ ), scientifically valid $(p<0.001)$, and that they would be more likely to 
Figure 2: Broad Support for Challenge Trials and Integrated Trials That Accelerate COVID-19 Vaccine Development

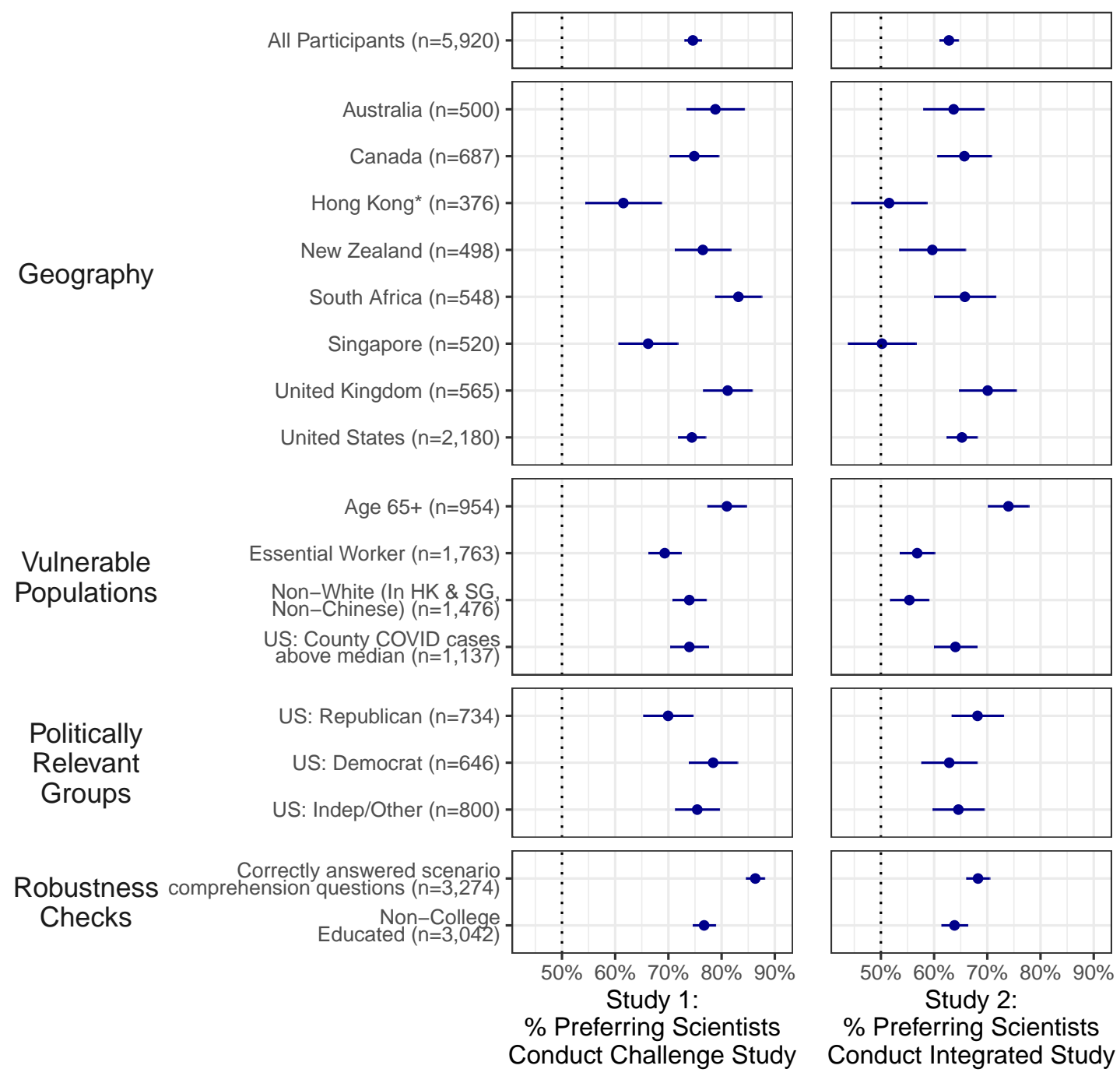

Notes: The Figure shows the percent of respondents who preferred that scientists conduct each accelerated trial instead of a standard trial. Study 1 considered the use of a challenge trial in which participants are intentionally exposed to the virus instead of, in a standard trial, waiting for participants to be exposed to it in their daily lives. Study 2 considered the integration of smaller Phase II safety and immunogenicity trials into larger Phase III efficacy trials instead of, in a standard trial, waiting for the completion of a Phase II safety and immunogenicity trial before commencing a Phase III efficacy trial. The Figure shows the mean proportion of respondents who say they would prefer scientists to conduct each accelerated design for each study overall, by geography, and across various demographic subgroups. 95\% confidence intervals surround the point estimates. Sample sizes shown are totals across both studies; respondents are approximately evenly split across the two studies. See Tables S3, S4, $S 7$, and $S 8$ for numerical values.

* This Figure presents non-white respondents from Hong Kong only. There were an unanticipatedly large number of participants in Hong Kong who indicated they were white. The 2016 Hong Kong Census estimates that only $0.8 \%$ of the Hong Kong population identifies as white; we discuss this issue in further detail in the Supplementary Materials. 


\footnotetext{
${ }^{3}$ We caution against any strong interpretations of how this result would map to likely behavior, but find it reassuring that participants did not on average say they were less likely to take the vaccine if a challenge trial were used. Moreover, the minority of the sample that said they thought vaccines were "dangerous" in general were essentially indifferent between the trial types.
} 
Figure 3: Vast Majority of Survey Respondents Describe Both Accelerated Designs as Ethical

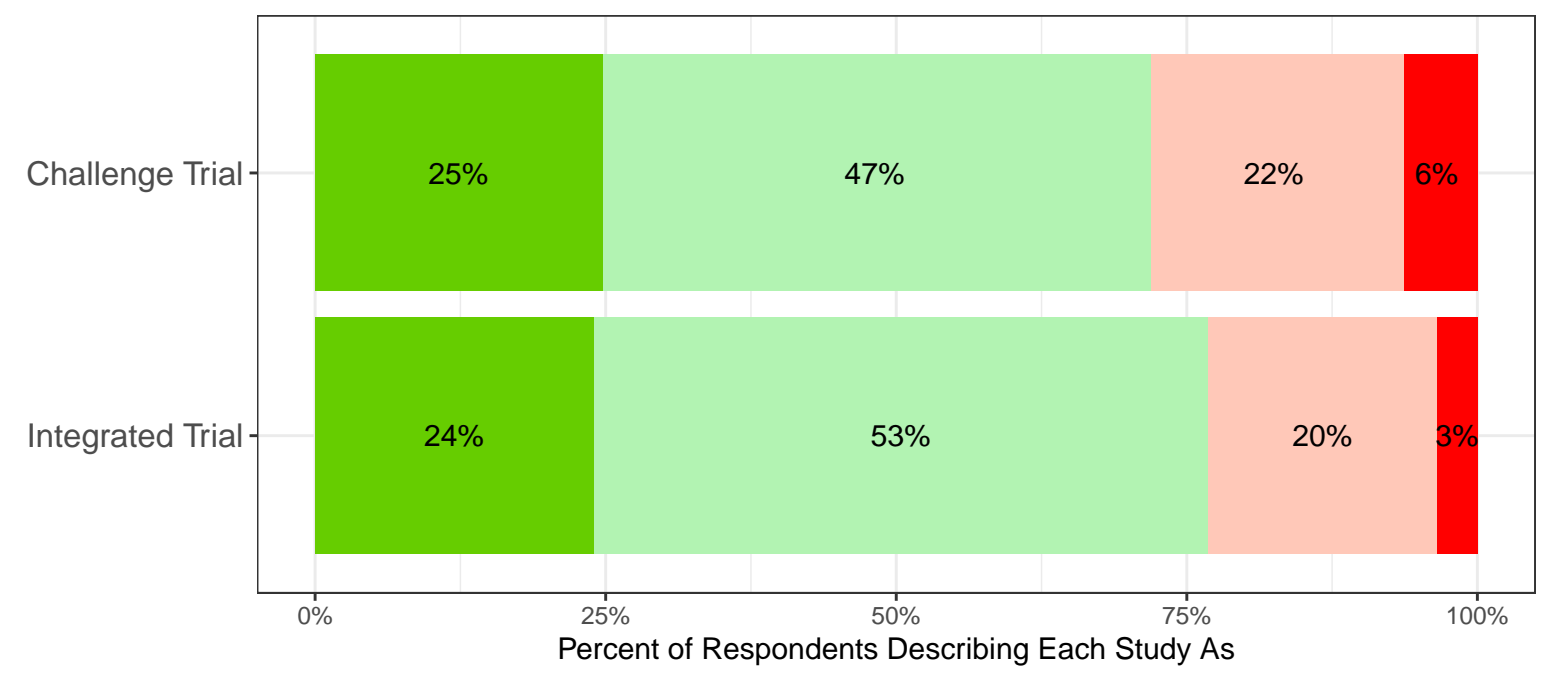

Definitely ethical Probably ethical Probably unethical

Definitely unethical

designs on average, this suggests it is unlikely that there exists a subpopulation very strongly opposed to accelerated designs that we undersample by a factor of 2.78 or 1.68 (for challenge and integrated, respectively).

To further assess this potential concern, we also conducted a placebo test by comparing our US sample with nationally-representative samples from the Pew Research Center and Gallup on items related to vaccine safety and scientific knowledge. First, Gallup data finds that $86 \%$ of Americans say that vaccines are not "more dangerous than the diseases they are designed to prevent" [30]; in our US sample, this number is 83\%. Second, probing scientific knowledge more generally, Pew data finds that $76 \%$ of Americans know that ocean tides are caused by the pull of the moon and that $72 \%$ of Americans know that cell phones use radio waves [31]; in our US sample, these figures are $77 \%$ and $73 \%$, respectively. That our sample closely reflects other, nationally representative samples on these benchmarks is encouraging for the external validity of our findings. 
The results of the sensitivity analysis, which bounds unobserved bias, the lack of observed heterogeneity of responses across observable characteristics, and the close resemblance of our sample to other samples on related dimensions therefore all indicate that sampling bias is very unlikely to account for our results.

\section{Discussion}

We conducted large-N surveys in eight countries to gather systematic data about public support for accelerated COVID-19 vaccine trial designs. Our results suggest that there is broad public support across nations and demographics for accelerating COVID-19 vaccine trials through integrated Phase II and III trials, and especially through challenge trials. A majority of our respondents preferred the use of these accelerated designs and saw them as ethical. Indeed, on average our respondents found challenge trials to be more likely to be ethical than standard trials. These results are consistent among every subgroup we examined, including many vulnerable populations of interest, across the countries we surveyed, and across many plausible vaccine trial design details. While the vast majority of participants in our survey understood the key differences between the designs we described, it is of particular note that, among those who did understand them, fully $86 \%$ and $68 \%$ preferred for scientists to conduct challenge and integrated trials, respectively.

While our results do not at all settle the complex ethical debate about these accelerated trials, nor do they address the scientific or technical questions surrounding their use, they do bolster the case for these trials.

First, many scholars and the WHO have called for consulting the public regarding COVID19 vaccine trial designs [12, 13, 16] given the longstanding view that part of what determines whether proposed research is ethical is whether the affected community supports the research [19,20]. Our results suggest the public in multiple countries is broadly supportive of accelerated 
trial designs in this instance and sees them as ethical.

Second, our results help diminish the worry that, by appearing unethical, these designs would undermine public trust in vaccines, or in a resulting COVID-19 vaccine. Indeed, respondents said they would be more likely to take a vaccine that had been tested using a challenge instead of a conventional trial. Although this survey-based self-report should not be interpreted as likely diagnostic of future behavior, it can help assuage concerns that a challenge trial would undermine public willingness to take a COVID-19 vaccine. While our results do not directly speak to how the public would react to a severe adverse event in a challenge trial, it should be noted that such events are also possible in conventional trails, and potentially even likelier to occur given their larger sample sizes.

Finally, our results can provide some reassurance to policymakers and regulators concerned about potential negative public sentiment towards the use of these designs.

Our results have several limitations worth noting. First, our sample came from an online survey panel. Unfortunately, we determined that gathering a random probability sample would have required significant delay, past the point at which findings about public opinion could inform ongoing decision-making. That said, previous work has found that the sample we used is demographically representative and that a number of political, psychological, and experimental results replicate on it [26]. Moreover, the robustness of our results across geographies and demographic subgroups suggest it is unlikely that a different survey sampling approach in these geographies would produce qualitatively different results [32]. Finally, our sensitivity analyses and placebo tests empirically suggested that sampling bias was very unlikely to account for our results. Still, our data is likely to exclude those without internet access who therefore could not take our survey.

Second, although our survey found relatively consistent results in English-speaking countries worldwide, it is possible that results could differ in other locales [24]. The results could 
also change if they were re-run at a different time. The surveys were fielded in May 2020, prior to the commencement of Phase 3 trials, which may change how the public weighs the risks and benefits of the accelerated designs.

Third, when individuals consider moral dilemmas, they typically weigh ethical costs and benefits more, and their initial emotional reactions less, when they engage in more careful considerations of the alternatives at hand [33]. Our study participants spent a median of 176 seconds reading about the trial design and answering our primary and secondary outcome questions. This probably reflects less time and engagement than would be present were our respondents to deliberate with others [34], but potentially more than, e.g., when reading a news article. Consistent with the possibility that individuals would weigh social benefits even more (and thus prefer accelerated designs to an even greater extent) were they to engage in more deliberate reflection, Gbesemete et al. find even stronger public support for challenge trials in focus groups conducted with 57 young people in the UK [25]. This suggests that methods that facilitate additional participant education and deliberation, such as focus groups, may find even greater public support for accelerated designs than we found. Future work should nevertheless continue to assess the extent to which conclusions might change if individuals were to encounter information about these trial designs in other settings.

Fourth, explaining these trial designs to laypeople necessarily involved making judgments about how to describe the trials amidst scientific uncertainty surrounding the likely designs and their risks. However, we found that our respondents did largely understand the key trade-offs involved and that their support was consistent across the alternative assumptions and scenarios we presented. Nevertheless, scientific and technical knowledge about COVID-19 and associated vaccines is also evolving rapidly, and, although our results were consistent across many design details, it will be critical for future work to explore the robustness of public support for challenge studies and other trial designs across different conditions, especially if assessments of overall 
risks to participants or benefits to society change dramatically.

Finally, although we did demonstrate the robustness of our results across many possible trial design details, there are remaining questions we did not ask respondents and that future research should consider.

First, might respondents have preferred the accelerated designs to the standard designs even if they were not faster than the standard designs? For example, in challenge trials, fewer participants receive the experimental vaccine; participants may prefer the challenge trial for this reason. In our studies, we always presented respondents with scenarios that stated that the accelerated designs were expected to produce a vaccine faster than a standard design, so our data do not speak to the question of whether respondents would still prefer the accelerated designs were they not to accelerate the vaccine approval timeline. However, we did find that respondents were not particularly sensitive to how many months the accelerated design was able to accelerate the vaccine approval timeline, especially in the case of challenge trials (see Tables S5 and S9). This is consistent with the plausibility of the hypothesis that some respondents preferred the accelerated designs for reasons unrelated to their accelerated timeline. Our research offers a blueprint for future research that can and should consider whether the public finds accelerated designs preferable even if they do not accelerate vaccine testing timelines. There are also alternative trial designs that we did not include in our surveys, such as enrolling very large samples in Phase 3 designs to speed up the testing timeline and adaptive designs, that future research could consider as well.

Additionally, COVID-19 challenge trials in healthy, young volunteers would probably be supplemented by additional safety testing in more diverse populations; to keep the scenarios relatively concise we did not describe this detail to respondents. Our work also leaves open questions about how the public would react to unforeseen adverse events during accelerated vaccine trials and whether such events would have different effects on public trust than adverse 
events in conventional trials, public perception of combinations of these accelerated designs, preferences between them, and between them and other accelerated designs, such as adaptive integrated trials [6]. However, our findings do show that it is possible to successfully explain relevant ethical trade-offs in trial design to a global public, and that people in many geographies broadly prefer approaches that accelerate COVID-19 vaccine trial timelines.

\section{Contributors}

All authors attest they meet the ICMJE criteria for authorship. All authors contributed to conceptualization and study design. DB, JK, and AG wrote the first draft of the manuscript. DB and JK contributed to the data collection and analysis. All authors contributed to critical revision of the manuscript for important intellectual content and gave final approval. DB and JS contributed funding.

\section{Conflicts of Interest}

All authors declare no competing interests.

\section{Acknowledgements}

The data collection was funded by the University of California, Berkeley. NE and MM are supported by the National Institute of Allergy and Infectious Diseases of the National Institutes of Health (\#R01 AI114617). The funders did not influence any aspect of our research or decision to submit.

\section{References}

[1] James K. Jackson, Martin A. Weiss, Andres B. Schwarzenberg, and Rebecca M. Nelson. Global economic effects of covid-19. Technical report, 2020. 
[2] World Health Organization. Draft landscape of covid-19 candidate vaccines. Available at https://www.who.int/who-documents-detail/ draft-landscape-of-covid-19-candidate-vaccines, July 2020.

[3] Nir Eyal, Marc Lipsitch, and Peter G Smith. Human challenge studies to accelerate coronavirus vaccine licensure. The Journal of Infectious Diseases, 2020.

[4] Meta Roestenberg, Ingrid Kamerling, and Saco J de Visser. Controlled human infections as a tool to reduce uncertainty in clinical vaccine development. Frontiers in medicine, 5: 297, 2018.

[5] Qing Liu and Gordon W Pledger. Phase 2 and 3 combination designs to accelerate drug development. Journal of the American Statistical Association, 100(470):493-502, 2005.

[6] Scott M Berry, Bradley P Carlin, J Jack Lee, and Peter Muller. Bayesian adaptive methods for clinical trials. CRC press, 2010.

[7] Stanley A Plotkin and Arthur Caplan. Extraordinary diseases require extraordinary solutions. Vaccine, 2020.

[8] Jon Cohen. Speed coronavirus vaccine testing by deliberately infecting volunteers? not so fast, some scientists warn. Science, March 2020.

[9] Lawrence Corey, John R Mascola, Anthony S Fauci, and Francis S Collins. A strategic approach to covid-19 vaccine r\&d. Science, 2020.

[10] Meagan E Deming, Nelson L Michael, Merlin Robb, Myron S Cohen, and Kathleen M Neuzil. Accelerating development of sars-cov-2 vaccines- the role for controlled human infection models. New England Journal of Medicine, 2020. 
[11] World Health Organization. Feasibility, potential value and limitations of establishing a closely monitored challenge model of experimental covid-19 infection and illness in healthy young adult volunteers. Technical report, World Health Organization, 2020.

[12] World Health Organization. Key criteria for the ethical acceptability of covid-19 human challenge studies. Technical report, World Health Organization, 2020.

[13] Seema K Shah, Franklin G Miller, Thomas C Darton, Devan Duenas, Claudia Emerson, H Fernandez Lynch, Euzebiusz Jamrozik, Nancy S Jecker, Dorcas Kamuya, Melissa Kapulu, et al. Ethics of controlled human infection to study covid-19. Science, 368(6493): 832-834, 2020.

[14] Adair D Richards. Ethical guidelines for deliberately infecting volunteers with covid-19. Journal of Medical Ethics, 2020.

[15] Ariella Binik. What risks should be permissible in controlled human infection model studies? Bioethics, 2020.

[16] Euzebiusz Jamrozik and Michael J Selgelid. Covid-19 human challenge studies: ethical issues. The Lancet Infectious Diseases, 2020.

[17] Robert Steel, Lara Buchak, and Nir Eyal. Why continuing uncertainties are no reason to postpone challenge trials for coronavirus vaccines. Journal of Medical Ethics, 2020.

[18] Adam J Kolber. Why we (probably) must deliberately infect. Journal of Law and the Biosciences, Forthcoming, 2020.

[19] SK Shah, J Kimmelman, A Drapkin Lyerly, H Fernandez Lynch, F McCutchan, FG Miller, R Palacios, C Pardo-Villamizar, and C Zorrilla. Ethical considerations for zika virus hu- 
man challenge trials. National Institutes of Health, National Institute of Allergy and Infectious Diseases: Seattle, WA, USA, 2017.

[20] Robert Klitzman. Institutional review board community members: who are they, what do they do, and whom do they represent? Academic medicine: journal of the Association of American Medical Colleges, 87(7):975, 2012.

[21] Heidi J Larson, Louis Z Cooper, Juhani Eskola, Samuel L Katz, and Scott Ratzan. Addressing the vaccine confidence gap. The Lancet, 378(9790):526-535, 2011.

[22] Seema K Shah, Franklin G Miller, Thomas C Darton, Devan Duenas, Claudia Emerson, Holly Fernandez Lynch, Euzebiusz Jamrozik, Nancy S Jecker, Dorcas Kamuya, Melissa Kapulu, et al. Unnecessary hesitancy on human vaccine tests-response. Science (New York, NY), 369(6500):151, 2020.

[23] Alan S Gerber, Eric M Patashnik, David Doherty, and Conor Dowling. A national survey reveals public skepticism about research-based treatment guidelines. Health Affairs, 29 (10):1882-1884, 2010.

[24] Edmond Awad, Sohan Dsouza, Azim Shariff, Iyad Rahwan, and Jean-François Bonnefon. Universals and variations in moral decisions made in 42 countries by 70,000 participants. Proceedings of the National Academy of Sciences, 117(5):2332-2337, 2020.

[25] D Gbesemete, M Barker, WT Lawrence, D Watson, H de Graaf, and RC Read. Exploring the acceptability of controlled human infection with sarscov2-a public consultation. BMC medicine, 18(1):1-8, 2020.

[26] Alexander Coppock and Oliver A McClellan. Validating the demographic, political, psychological, and experimental results obtained from a new source of online survey respondents. Research \& Politics, 6(1):2053168018822174, 2019. 
[27] Henrik Salje, Cécile Tran Kiem, Noémie Lefrancq, Noémie Courtejoie, Paolo Bosetti, Juliette Paireau, Alessio Andronico, Nathanaël Hozé, Jehanne Richet, Claire-Lise Dubost, et al. Estimating the burden of sars-cov-2 in france. Science, 2020.

[28] Robert Verity, Lucy C Okell, Ilaria Dorigatti, Peter Winskill, Charles Whittaker, Natsuko Imai, Gina Cuomo-Dannenburg, Hayley Thompson, Patrick GT Walker, Han Fu, et al. Estimates of the severity of coronavirus disease 2019: a model-based analysis. The Lancet Infectious Diseases, 2020.

[29] Paul R Rosenbaum. Observational Studies. Springer, New York, 2002.

[30] Gallup. Fewer in u.s. continue to see vaccines as important. Available at https://news.gallup.com/poll/276929/ fewer-continue-vaccines-important.aspx, 2020.

[31] Pew Research Center. A look at what the public knows and does not know about science. Available at https://www.pewresearch.org/science/2015/09/10/ what-the-public-knows-and-does-not-know-about-science/, 2015.

[32] Alexander Coppock, Thomas J Leeper, and Kevin J Mullinix. Generalizability of heterogeneous treatment effect estimates across samples. Proceedings of the National Academy of Sciences, 115(49):12441-12446, 2018.

[33] Joshua D Greene, Sylvia A Morelli, Kelly Lowenberg, Leigh E Nystrom, and Jonathan D Cohen. Cognitive load selectively interferes with utilitarian moral judgment. Cognition, 107(3):1144-1154, 2008.

[34] Scott YH Kim, Ian F Wall, Aimee Stanczyk, and Raymond De Vries. Assessing the public's views in research ethics controversies: deliberative democracy and bioethics as natural allies. Journal of Empirical Research on Human Research Ethics, 4(4):3-16, 2009. 


\section{Supplementary Materials: Broad Cross-National Public Support for Accelerated COVID-19 Vaccine Trials}

\section{Contents}

Additional Detail on Survey 1

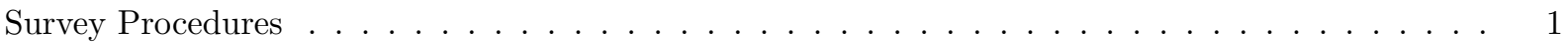

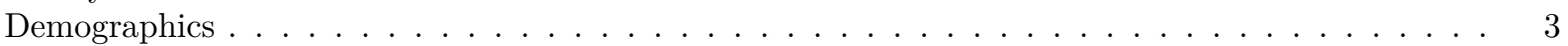

Full Survey Questions and Results 3

Study 1: Challenge Trial . . . . . . . . . . . . . . . . . . . . . . . 3

Study 2 Integrated Trial $\ldots \ldots \ldots \ldots \ldots \ldots \ldots \ldots \ldots$

$\begin{array}{lr}\text { Pre-Registration } & 19\end{array}$

Departures from Pre-Registration . . . . . . . . . . . . . . . . . . . . . . . 19

Pre-Registration Document . . . . . . . . . . . . . . . . . . . . . . . 19

\section{Additional Detail on Survey}

\section{Survey Procedures}

Before conducting the surveys, we filed a pre-registration and pre-analysis plan at https://osf.io/cgbxa/, the full text of which is available at the end of the SM. We describe two minor departures from our pre-registered pre-analysis plan in the last section.

We then conducted national surveys in Australia, Canada, Hong Kong, New Zealand, South Africa, Singapore, the United Kingdom, and the United States. We recruited participants online using the sample provider Lucid in early May, 2020. Survey respondents in Australia, the United Kingdom, and the United States surveys were selected to match Census benchmarks. We requested 2,000 participants in the United States and 500 for each other geography. Respondents must take the survey on a desktop computer and be able to read English.

In the survey, we first asked for consent to participate. 471 participants did not consent and were removed from the survey. 164 participants failed a first attention check, which asked participants to select "I understand" in response to "For our research, careful attention to survey questions is critical!"; these participants were removed. As a final attention check, we wrote: "People are very busy these days and many do not have time to follow what goes on in the government. We are testing whether people read questions. To show that you've read this much, answer both 'extremely interested' and 'very interested."' We removed 1,636 participants for not reading carefully enough to select both 'extremely interested' and 'very interested'. 895 did not complete the survey. 5,920 participants remained and completed the survey.

We then told participants:

COVID-19, often called coronavirus, has led to hundreds of thousands of deaths and millions of job losses.

Many experts say that people will continue dying of coronavirus and daily life will not return to normal until there is a vaccine. A vaccine would make many people immune to coronavirus, so 
they could not catch coronavirus or give it to other people.

Politicians and experts are debating several approaches to developing a coronavirus vaccine. These approaches are all medically and scientifically valid, but have different strengths and weaknesses. Because the coronavirus crisis affects everyone, many politicians and experts want to know what people think about the best approach. We would like to hear your opinion about which of two approaches you think the government and researchers should take. We plan to share our findings, so please take this survey seriously.

Do you understand?

We then gave the following background on vaccines:

To test whether a new coronavirus vaccine is safe and effective, scientists will accept volunteers for a study on vaccines. Scientists then will use a device (like flipping a coin) that randomly assigns volunteers in the study to either receive the vaccine or a placebo, a safe substance like salt water that does not have any vaccine in it. The scientists will then monitor whether study participants who received the vaccine instead of the placebo are less likely to get the coronavirus. Scientists will know the vaccine works if the participants who received the vaccine were less likely to get coronavirus than the people who received the placebo.

Do you understand?

We then asked two questions on people's general views on vaccines: "In your opinion, how important is it that parents get their children vaccinated?" and "Do you think vaccines are more dangerous than the diseases they are designed to prevent, or not?"

We then randomized participants to one of two studies: Study 1, about Challenge Trials, and Study 2, about Integrated Trials. We always began:

We would first like to get your opinion about two hypothetical ways to do a study to determine whether a new coronavirus vaccine is effective.

- There have already been initial studies that gave the vaccine to a small number of volunteers. In these initial studies, the vaccine appeared safe. [For challenge trial only: These initial studies also found that the vaccine has a good chance of working, even if it has not been proven effective yet.]

- For both of the studies we will describe, people have already volunteered to participate. Both studies are practical to start right away.

- People who volunteered to participate in the studies were fully informed about what each study involved before they volunteered.

- If any participants get sick during the studies, their medical care and any lost wages would be paid for. They would also have access to remdesivir, a drug that can often, but not always, improve time to recovery.

We described both studies as practical to begin to ensure respondents did not select on the basis of perceived practicability, as the ethical question is only of interest if both trials are practical to conduct.

We show how we described the trial designs to participants and the outcome variables in the context of the studies below. We did not allow participants to move on from the page describing the trial design until at least 60 seconds had gone by.

We finished the survey with a series of demographic questions regarding age, gender, education, political ideology, employment, religiosity, scientific knowledge, race/ethnicity, and, in the United States only, political party identification and zip code. 


\section{Demographics}

Survey participants reported the demographic characteristics shown in Table S1. As expected for an online sample, the survey participants are slightly more educated than the population at large on average. Later we show the results are consistent for participants without a college degree. Survey respondents in Australia, the United Kingdom, and the United States surveys were selected to match Census benchmarks on age, gender, and race and ethnicity, but this was not possible in the other geographies. Finally, for the US sample, we later present an analysis weighting our sample to be representative of the US population; the findings do not change. Sample sizes and demographics shown are for the entire sample across both studies; respondents were randomly assigned to the two studies with equal probabilitiy, so are approximately evenly split across the two studies.

Table S1: Survey Demographics by Geography

\begin{tabular}{l|l|l|l|l|l|l|l|l|l}
\hline & AUS & CAN & HK & NZ & SA & SG & UK & US & All \\
\hline Average Age & 49 & 47 & 33 & 44 & 36 & 33 & 43 & 49 & 44 \\
\hline \% Female & 52 & 52 & 48 & 45 & 46 & 47 & 47 & 63 & 54 \\
\hline \% College Graduate & 43 & 46 & 64 & 39 & 35 & 61 & 47 & 51 & 49 \\
\hline \% Non-White (In HK \& SG, Non-Chinese) & 20 & 27 & 25 & 27 & 53 & 21 & 16 & 21 & 25 \\
\hline \% Employed as an Essential Worker & 24 & 25 & 67 & 22 & 27 & 43 & 22 & 27 & 30 \\
\hline \% Employed as a Non-Essential Worker & 25 & 26 & 15 & 28 & 24 & 28 & 31 & 19 & 23 \\
\hline \% Unemployed due to COVID & 5 & 4 & 1 & 4 & 10 & 2 & 3 & 6 & 5 \\
\hline \% Furloughed due to COVID & 4 & 7 & 3 & 8 & 12 & 5 & 12 & 5 & 7 \\
\hline $\mathrm{N}$ & 500 & 687 & 422 & 498 & 548 & 520 & 565 & 2,180 & 5,920 \\
\hline
\end{tabular}

For the US sample, relevant questions also closely match national averages from other surveys:

- Gallup data from December 2019 finds that $86 \%$ of Americans say that vaccines are not "more dangerous than the diseases they are designed to prevent"; in our US sample, this number is $83 \%$. (In our sample outside the US, this figure is $80 \%$.)

- Pew data from September 2014 finds that $76 \%$ of Americans know that ocean tides are caused by the pull of the moon and that $72 \%$ of Americans know that cell phones use radio waves; in our US sample, these figures are $77 \%$ and $73 \%$, respectively. (In our sample outside the US, these figures are $73 \%$ and $75 \%$.)

\section{Full Survey Questions and Results}

\section{Study 1: Challenge Trial}

\section{Vaccine Study Design Description}

After the preamble quoted above, participants were shown a table that looks like the example given in Figure S1. All of the highlighted elements were randomized. We did not allow participants to move on from the page describing the trial design until at least 60 seconds had gone by.

The example in Figure S1 shows the results of one particular randomization. All the highlighted numbers in the example were randomized, as detailed below. (These highlights did not appear for respondents.) In the below, the bolded numbers correspond with the numbers used in the example in Figure S1. We randomized these parameters given uncertainty about how particular vaccine trials might be conducted, to ensure our findings were not sensitive to any of these parameters.

- Standard Design Trial N: $(3,000 ; 5,000 ; 7,000 ; \mathbf{9 , 0 0 0} ; 11,000)$

$-\mathrm{N}$ in each condition is calculated as half of this number. 


\begin{tabular}{|c|c|c|c|}
\hline Name & Study A & Study B & Key Differences \\
\hline $\begin{array}{c}\text { Study } \\
\text { procedures }\end{array}$ & $\begin{array}{l}\text { 1. Recruit } 80 \text { healthy volunteers aged } 18 \text { - } \\
30 \text { to participate. } \\
\text { 2. Give } 40 \text { people the vaccine and another } \\
40 \text { people a placebo. } \\
\text { 3. Scientists expose all } 80 \text { participants to } \\
\text { the coronavirus. Scientists keep these } \\
\text { participants in a medical research center } \\
\text { where they cannot infect others, are } \\
\text { closely monitored, and provided any } \\
\text { necessary medical care. } \\
\text { 4. Scientists monitor participants for } \\
\text { several weeks to learn if the vaccine } \\
\text { works. }\end{array}$ & $\begin{array}{l}\text { 1. Recruit } 9,000 \text { healthy } \\
\text { volunteers to participate. } \\
\text { 2. Give } 4,500 \text { people the vaccine } \\
\text { and another } 4,500 \text { people a } \\
\text { placebo. } \\
\text { 3. All participants then go about } \\
\text { their daily lives. Scientists } \\
\text { monitor participants for several } \\
\text { months to learn if the vaccine } \\
\text { works. }\end{array}$ & $\begin{array}{l}\text { - In Study B, people } \\
\text { catch the coronavirus } \\
\text { on their own as they go } \\
\text { about their daily } \\
\text { lives. In Study A, } \\
\text { participants are } \\
\text { intentionally exposed to } \\
\text { the virus. }\end{array}$ \\
\hline $\begin{array}{c}\text { Risks to } \\
\text { study } \\
\text { participants }\end{array}$ & $\begin{array}{l}\text { - } 40 \text { participants in the placebo group are } \\
\text { intentionally exposed to coronavirus } \\
\text { while quarantined in a medical research } \\
\text { center. Because all participants in this } \\
\text { study are young people, it is unlikely any } \\
\text { would develop serious complications. In } \\
\text { addition, participants would likely } \\
\text { develop immunity, so are unlikely to get } \\
\text { coronavirus again or pass it along to } \\
\text { others. } \\
\text { - } 40 \text { participants who received the vaccine } \\
\text { are also intentionally exposed to } \\
\text { coronavirus. If the vaccine in the } \\
\text { study does not work, they would also get } \\
\text { coronavirus. In the worst-case scenario, } \\
\text { they could get an especially bad case of it. } \\
\text { - It is very unlikely any study participants } \\
\text { would die of coronavirus. }\end{array}$ & $\begin{array}{l}\text { - } 90 \text { participants in the placebo } \\
\text { group are expected to get } \\
\text { coronavirus from their daily lives. } \\
\text { - It is likely } 1 \text { participant would } \\
\text { die of coronavirus. } \\
\text { - If the vaccine in the study does } \\
\text { not work, } 90 \text { participants who } \\
\text { received the vaccine would also } \\
\text { get coronavirus. In the worst-case } \\
\text { scenario, they could get an } \\
\text { especially bad case of it. }\end{array}$ & $\begin{array}{l}\text { If the vaccine works: } \\
\text { - } 50 \text { more volunteers } \\
\text { catch the coronavirus in } \\
\text { Study B. } \\
\text { - } 1 \text { more volunteer } \\
\text { would die in Study B. }\end{array}$ \\
\hline $\begin{array}{l}\text { Expected } \\
\text { time until } \\
\text { vaccine } \\
\text { ready }\end{array}$ & $\begin{array}{l}\text { If the vaccine works, it would start being } \\
\text { distributed widely in } 6 \text { months from } \\
\text { today, November } 2020 \text {. }\end{array}$ & $\begin{array}{l}\text { If the vaccine works, it would } \\
\text { start being distributed widely in } \\
12 \text { months from today, May } 2021 \text {. }\end{array}$ & $\begin{array}{l}\text { - If the vaccine works, } \\
\text { Study A would allow it } \\
\text { to be ready } 6 \text { months } \\
\text { sooner than Study B. }\end{array}$ \\
\hline $\begin{array}{l}\text { Benefits to } \\
\text { society, if } \\
\text { the vaccine } \\
\text { works }\end{array}$ & $\begin{array}{l}\text { During the } 6 \text { months between now and } \\
\text { when the vaccine is ready, it is estimated } \\
\text { that: } \\
\text { - } 1,200,000 \text { people will die from } \\
\text { coronavirus. } \\
\text { - Millions of people will remain out of } \\
\text { work. } \\
\text { However, once the vaccine is ready and } \\
\text { starts reaching all those who need it in } \\
\text { November } 2020 \text { : } \\
\text { - Very few people will die of coronavirus } \\
\text { any more. } \\
\text { - Daily life and the economy will return } \\
\text { to normal. }\end{array}$ & $\begin{array}{l}\text { During the } 12 \text { months between } \\
\text { now and when the vaccine is } \\
\text { ready, it is estimated that: } \\
\text { - } 2,400,000 \text { people will die from } \\
\text { coronavirus. } \\
\text { - Millions of people will remain } \\
\text { out of work. } \\
\text { However, once the vaccine is } \\
\text { ready and starts reaching all those } \\
\text { who need it in May } 2021 \text { : } \\
\text { - Very few people will die of } \\
\text { coronavirus any more. } \\
\text { - Daily life and the economy will } \\
\text { return to normal. }\end{array}$ & $\begin{array}{l}\text { - With Study A, } \\
1,200,000 \text { lives are } \\
\text { saved. } \\
\text { - With Study A, people } \\
\text { can return to work and } \\
\text { daily life can return to } \\
\text { normal } 6 \text { months } \\
\text { sooner. }\end{array}$ \\
\hline
\end{tabular}

Figure S1: Example Stimulus, Study 1 (Study A is Challenge Trial in this example) 
- Challenge Trial N $(\mathbf{8 0} ; 100 ; 200)$

$-\mathrm{N}$ in each condition is calculated as half of this number.

- \% in Standard Design that are exposed to coronavirus in their daily lives (2\%,5\%, 20\%). This is calculated in the survey flow and not directly shown to participants.

- The number of participants who catch coronavirus is calculated as the product of this and the size of the standard trial placebo condition.

- $\%$ in Standard Design who die of coronavirus if they are exposed $(0.5 \%, \mathbf{1 \%})$. This is calculated in the survey flow and not directly shown to participants.

- The number of participants who die of coronavirus is calculated as the product of this and the number of participants who catch coronavirus, described above.

- How long the Standard Design takes to get a vaccine ready: 12 or 18 months.

- The date (e.g., May 2021), is calculated automatically based on the current date. The number of people in society who die (e.g., $\mathbf{2 , 4 0 0 , 0 0 0}$ ) is calculated by multiplying the number of months until a vaccine is ready by 200,000. 200,000 is a fixed variable for both study designs. We selected 200,000 deaths per month as that is approximately the number of COVID-19 deaths in April 2020, and so therefore represents a likely conservative estimate of likely COVID-19 deaths per month in the months ahead.

- How much faster the Challenge Trial is: 2, 4, or $\mathbf{6}$ months faster.

- The date the vaccine is ready if a challenge trial is used is the date above minus this number.

- Which design is described as "Study A" or "Study B". Whichever study was described as "Study A" always was shown in the first column.

We formed these parameters in consulatation with experts in vaccine trial design. The "In the worst-case scenario, they could get an especially bad case of it." language refers to the possibility that "an immune response to a vaccine can predispose an individual to a worse outcome upon infection" [2].

In the "Key Differences" column, the differences are taken based on the randomizations from Studies A and B. We always describe it as possible but unlikely that any participants in the challenge trial would die of coronavirus given findings that the IFR of people ages 18-30 from COVID-19 is 0.03\% [6, 7]. (In the largest challenge trial shown to participants $(\mathrm{N}=200)$, the probability that zero participants of 100 in the placebo condition would die of coronavirus is $(1-0.0003)^{100}=97 \%$.) Table S5, presented later, shows the results are consistent across parameters we used in describing the challenge and standard trials.

After reading this table, we then provided participants with a short summary of the key points. In the example in Figure S1, this would look as follows:

\section{Summary:}

- Study A:

- Study participants get coronavirus on their own as they go about their daily lives.

- [More study participants catch coronavirus and more of them likely die of it. / More study participants are likely to die of coronavirus. / Fewer study participants catch coronavirus, but more would likely die of it. / If the numbers are equal between the designs, this bullet is omitted.]

- It takes longer for the vaccine to be ready, so more people in society generally die of coronavirus.

- Study B:

- Young people volunteer to have scientists expose them to the coronavirus while they are in a medical research center.

- [Fewer study participants catch coronavirus. It is possible but very unlikely that any study participants would die of it. / More study participants catch coronavirus. It is possible but very unlikely that any study participants would die of it. / If the numbers are equal between the designs, this bullet is omitted.] 
- The vaccine is ready sooner, so fewer people die of coronavirus in society generally.

Whichever study was randomized to be Study A is always shown first. Which middle bullet in each scenario corresponding to which design has greater or fewer coronavirus cases and deaths in the trial is determined based on the randomization described above. The highlighted sections correspond with the version that would have been shown for the example in Figure S1.

Respondents then answered the questions that constitute our outcome measures. Next, on a separate page, they were asked to answer scenario comprehension questions to ensure they understood the studies.

Respondents could not return to the table when answering the scenario comprehension questions. Below we describe the outcome measures and scenario comprehension questions in more detail.

\section{Scenario Comprehension Outcomes}

We asked the following scenario comprehension questions to ensure participants, on average, paid attention and understood the survey:

- If the vaccine works, which of the two studies we asked about would result in the vaccine being approved and widely available sooner?

- If the vaccine works, which of the two studies we asked about would result in more people in society generally dying of coronavirus?

- Which of the two studies we asked about involves intentionally exposing participants to coronavirus while they are quarantined in a medical research center?

- Which of the two studies we asked about would result in more people in the study dying of coronavirus?

Responses are coded as " 1 " if the participant provided the correct answer and " 0 " if they coded the incorrect answer. Table S2 reports the average rate of correct answers overall and by geography.

There were an unanticipatedly large number of participants in Hong Kong who identified as white, and these participants gave distinctive responses to all the questions, affecting our average characterization of Hong Kong. The 2016 Hong Kong Census estimates that only 0.8\% of the Hong Kong population identifies as white [1], so we report the results for self-identified non-white and white Hong Kong participants separately. As Tables S2 and S6 show, self-identified whites in Hong Kong were especially unlikely to understand the scenarios correctly, suggesting this group of self-identified white Hong Kong residents may have been a subset of participants in Hong Kong who were answering the survey carelessly, including the racial identification question itself. Consistent with this interpretation, the median self-identified white participant in Hong Kong spent only 95 seconds reading the main study table (we forced participants to spend at least 60 seconds before they could advance), versus a median of 124 seconds in the rest of the Hong Kong sample and a median of 181 in the sample outside of Hong Kong.

Table S2 also shows the results for the US when weighting the sample to the 2019 US Census population estimates for gender, age, race, and education. We construct these weights using entropy balancing [3].

The $p$-values in Table $\mathrm{S} 2$ are from one-sample $t$-tests testing the null hypothesis that the rate of correct answers is equal to 0.5 , which is what would be expected from random guessing.

The vast majority of participants understood the scenarios. Later, in Table S4, we show that support for the challenge trial is strongest for those who correctly answered all the scenario comprehension questions. 
Table S2: Study 1 - Proportions Correctly Answering Scenario Comprehension Questions

\begin{tabular}{|c|c|c|c|c|c|c|c|c|c|c|c|c|c|}
\hline & \multicolumn{3}{|c|}{$\begin{array}{c}\text { Participants } \\
\text { Intentionally Infected } \\
\text { In Challenge Correct } \\
(0 / 1)\end{array}$} & \multicolumn{3}{|c|}{$\begin{array}{c}\text { Vaccine Is Ready } \\
\text { Faster With Challenge } \\
\text { Correct }(0 / 1)\end{array}$} & \multicolumn{3}{|c|}{$\begin{array}{l}\text { More Participants Die } \\
\text { In Which Study Correct } \\
(0 / 1)\end{array}$} & \multicolumn{3}{|c|}{$\begin{array}{c}\text { More People in Society } \\
\text { Die In Which Study } \\
\text { Correct }(0 / 1)\end{array}$} & \multirow[b]{2}{*}{$\mathrm{N}$} \\
\hline & Mean & $95 \%$ CI & $\mathrm{p}$ & Mean & $95 \%$ CI & $\mathrm{p}$ & Mean & $95 \% \mathrm{CI}$ & $\mathrm{p}$ & Mean & $95 \% \mathrm{CI}$ & $\mathrm{p}$ & \\
\hline All Participants & 0.84 & $0.82-0.85$ & 0 & 0.83 & $0.81-0.84$ & 0 & 0.67 & $0.65-0.69$ & 0 & 0.83 & $0.81-0.84$ & 0 & 2,988 \\
\hline AUS & 0.85 & $0.80-0.89$ & 0 & 0.83 & $0.78-0.88$ & 0 & 0.66 & $0.59-0.72$ & 0 & 0.84 & $0.79-0.89$ & 0 & 222 \\
\hline CAN & 0.85 & $0.81-0.89$ & 0 & 0.85 & $0.81-0.89$ & 0 & 0.68 & $0.63-0.73$ & 0 & 0.83 & $0.79-0.87$ & 0 & 346 \\
\hline HK (Non-White) & 0.75 & $0.68-0.81$ & 0 & 0.71 & $0.65-0.78$ & 0 & 0.57 & $0.50-0.64$ & 0.05 & 0.68 & $0.61-0.74$ & 0 & 182 \\
\hline HK (White) & 0.58 & $0.37-0.78$ & 0.44 & 0.5 & $0.29-0.71$ & 1 & 0.54 & $0.33-0.74$ & 0.7 & 0.58 & $0.37-0.78$ & 0.44 & 26 \\
\hline NZ & 0.82 & $0.78-0.87$ & 0 & 0.82 & $0.77-0.87$ & 0 & 0.63 & $0.57-0.69$ & 0 & 0.83 & $0.79-0.88$ & 0 & 255 \\
\hline SA & 0.88 & $0.85-0.92$ & 0 & 0.89 & $0.86-0.93$ & 0 & 0.72 & $0.67-0.78$ & 0 & 0.91 & $0.87-0.94$ & 0 & 285 \\
\hline SG & 0.79 & $0.75-0.84$ & 0 & 0.78 & $0.73-0.82$ & 0 & 0.59 & $0.54-0.65$ & 0 & 0.79 & $0.74-0.83$ & 0 & 281 \\
\hline UK & 0.84 & $0.80-0.88$ & 0 & 0.88 & $0.84-0.91$ & 0 & 0.75 & $0.70-0.80$ & 0 & 0.87 & $0.83-0.91$ & 0 & 281 \\
\hline US & 0.85 & $0.83-0.87$ & 0 & 0.83 & $0.81-0.85$ & 0 & 0.69 & $0.66-0.71$ & 0 & 0.83 & $0.81-0.86$ & 0 & 1,110 \\
\hline US, Weighted & 0.83 & $0.81-0.85$ & 0 & 0.82 & $0.79-0.84$ & 0 & 0.66 & $0.63-0.69$ & 0 & 0.81 & $0.78-0.83$ & 0 & 1,110 \\
\hline
\end{tabular}

\section{Primary and Secondary Outcomes}

We asked the following outcome measures:

- If you had to choose, which study would you rather have scientists conduct?

- How ethical do you think the studies are? (Asked for both trial designs)

- How scientifically valid do you think the studies are? (Asked for both trial designs)

- If the study found the vaccine worked and it was then approved by the government, how likely would you be to take the vaccine to protect yourself from coronavirus? (Asked for both trial designs)

We pre-specified the first as a primary outcome and the difference between the ratings for the challenge and standard trial designs as secondary outcomes. This difference indicates the extent to which the average respondent judged the challenge trial to be more ethical, scientifically valid, or likelier to be taken than the standard trial, with higher values indicating the challenge trial is more ethical, scientifically valid, or likelier to be taken.

Table S3 shows the overall results and results by geography on each of these dependent variables. We again separately report results for self-identified whites and non-whites in Hong Kong for the reasons described above. The $p$-value for the primary outcome is from one-sample $t$-tests testing the null hypothesis that the preference for challenge trials equals the preference for the standard design (0.5), which would indicate an equal number of participants selecting the challenge and standard trial designs. For the other outcomes, the $p$-values are from one-sample $t$-tests testing the null hypothesis that the mean is equal to 0 , meaning there is no difference between respondents' ratings of the challenge trial and standard design on the outcome measure at hand.

Table S3: Study 1 - Main Results, All Participants and by Participant Geography

\begin{tabular}{|c|c|c|c|c|c|c|c|c|c|c|c|c|c|}
\hline & \multicolumn{3}{|c|}{$\begin{array}{c}\text { Prefers Scientists } \\
\text { Conduct Challenge } \\
\text { Study }(0 / 1)\end{array}$} & \multicolumn{3}{|c|}{$\begin{array}{l}\text { How Ethical (1-4): } \\
\text { Challenge Minus } \\
\text { Standard }\end{array}$} & \multicolumn{3}{|c|}{$\begin{array}{l}\text { How Scientifically } \\
\text { Valid (1-4): Challenge } \\
\text { Minus Standard }\end{array}$} & \multicolumn{3}{|c|}{$\begin{array}{l}\text { Would Take Vaccine } \\
\text { (1-4): Challenge Minus } \\
\text { Standard }\end{array}$} & \multirow[b]{2}{*}{$\mathrm{N}$} \\
\hline & Mean & $95 \% \mathrm{CI}$ & $\mathrm{p}$ & Mean & $95 \% \mathrm{CI}$ & $\mathrm{p}$ & Mean & $95 \% \mathrm{CI}$ & $\mathrm{p}$ & Mean & $95 \% \mathrm{CI}$ & $\mathrm{p}$ & \\
\hline All Participants & 0.75 & $0.73-0.76$ & 0 & 0.06 & $0.02-0.10$ & 0.01 & 0.23 & $0.20-0.27$ & 0 & 0.14 & $0.11-0.17$ & 0 & 2,988 \\
\hline AUS & 0.79 & $0.73-0.84$ & 0 & 0.05 & $-0.10-0.19$ & 0.53 & 0.23 & $0.12-0.34$ & 0 & 0.07 & $-0.03-0.16$ & 0.15 & 222 \\
\hline CAN & 0.75 & $0.70-0.79$ & 0 & -0.05 & $-0.16-0.06$ & 0.39 & 0.14 & $0.05-0.24$ & 0 & 0.05 & $-0.02-0.13$ & 0.16 & 346 \\
\hline HK (Non-White) & 0.62 & $0.54-0.69$ & 0 & -0.02 & $-0.20-0.17$ & 0.86 & 0.18 & $0.03-0.32$ & 0.02 & 0.1 & $-0.05-0.25$ & 0.2 & 182 \\
\hline HK (White) & 0.42 & $0.22-0.63$ & 0.44 & 0.5 & $0.08-0.92$ & 0.02 & -0.27 & $-0.71-0.17$ & 0.22 & 0 & $-0.47-0.47$ & 1 & 26 \\
\hline $\mathrm{NZ}$ & 0.76 & $0.71-0.82$ & 0 & 0.18 & $0.04-0.31$ & 0.01 & 0.29 & $0.18-0.40$ & 0 & 0.25 & $0.16-0.35$ & 0 & 255 \\
\hline SA & 0.83 & $0.79-0.88$ & 0 & 0.25 & $0.09-0.41$ & 0 & 0.49 & $0.37-0.61$ & 0 & 0.37 & $0.27-0.47$ & 0 & 285 \\
\hline SG & 0.66 & $0.61-0.72$ & 0 & -0.1 & $-0.23-0.04$ & 0.17 & 0.17 & $0.05-0.28$ & 0 & 0.07 & $-0.04-0.17$ & 0.21 & 281 \\
\hline UK & 0.81 & $0.77-0.86$ & 0 & 0.1 & $-0.04-0.24$ & 0.15 & 0.23 & $0.13-0.33$ & 0 & 0.09 & $-0.00-0.18$ & 0.06 & 281 \\
\hline US & 0.74 & $0.72-0.77$ & 0 & 0.05 & $-0.02-0.11$ & 0.14 & 0.22 & $0.16-0.28$ & 0 & 0.15 & $0.10-0.20$ & 0 & 1,110 \\
\hline US, Weighted & 0.73 & $0.71-0.76$ & 0 & 0.07 & $0.00-0.14$ & 0.04 & 0.21 & $0.16-0.27$ & 0 & 0.14 & $0.09-0.19$ & 0 & 1,110 \\
\hline
\end{tabular}


Table S4 shows that the results are similar across a variety of vulnerable populations, those who answered all the scenario comprehension questions correctly, and various politically relevant subgroups. We also examine a racial subgroup that is defined as non-white in Australia, Canada, New Zealand, the United Kingdom, and the United States, and as non-Chinese in Hong Kong and Singapore. The not college educated subgroup was not pre-specified, but is shown to demonstrate that our conclusions are not driven by the fact that our sample is slightly more educated than the general population.

Table S4: Study 1 - Main Results within Demographic Subgroups

\begin{tabular}{|c|c|c|c|c|c|c|c|c|c|c|c|c|c|}
\hline & \multicolumn{3}{|c|}{$\begin{array}{c}\text { Prefers Scientists } \\
\text { Conduct Challenge } \\
\text { Study }(0 / 1)\end{array}$} & \multicolumn{3}{|c|}{$\begin{array}{c}\text { How Ethical (1-4): } \\
\text { Challenge Minus } \\
\text { Standard }\end{array}$} & \multicolumn{3}{|c|}{$\begin{array}{c}\text { How Scientifically } \\
\text { Valid (1-4): Challenge } \\
\text { Minus Standard }\end{array}$} & \multicolumn{3}{|c|}{$\begin{array}{l}\text { Would Take Vaccine } \\
(1-4): \text { Challenge Minus } \\
\text { Standard }\end{array}$} & \multirow[b]{2}{*}{$\mathrm{N}$} \\
\hline & Mean & $95 \% \mathrm{CI}$ & $\mathrm{p}$ & Mean & $95 \% \mathrm{CI}$ & $\mathrm{p}$ & Mean & $95 \% \mathrm{CI}$ & $\mathrm{p}$ & Mean & $95 \% \mathrm{CI}$ & $\mathrm{p}$ & \\
\hline All Participants & 0.75 & $0.73-0.76$ & 0 & 0.06 & $0.02-0.10$ & 0.01 & 0.23 & $0.20-0.27$ & 0 & 0.14 & $0.11-0.17$ & 0 & 2,988 \\
\hline \multicolumn{14}{|l|}{ Vulnerable Populations } \\
\hline Age $65+$ & 0.81 & $0.77-0.85$ & 0 & 0.17 & $0.08-0.26$ & 0 & 0.28 & $0.19-0.36$ & 0 & 0.17 & $0.10-0.25$ & 0 & 447 \\
\hline Essential Worker & 0.69 & $0.66-0.72$ & 0 & -0.01 & $-0.08-0.07$ & 0.88 & 0.19 & $0.13-0.26$ & 0 & 0.09 & $0.03-0.15$ & 0 & 883 \\
\hline Non-White (In HK \& SG, Non-Chinese) & 0.74 & $0.71-0.77$ & 0 & 0.05 & $-0.04-0.15$ & 0.25 & 0.23 & $0.15-0.30$ & 0 & 0.2 & $0.14-0.27$ & 0 & 748 \\
\hline US: County cases >median & 0.74 & $0.70-0.77$ & 0 & 0.04 & $-0.05-0.14$ & 0.37 & 0.22 & $0.14-0.30$ & 0 & 0.17 & $0.10-0.24$ & 0 & 587 \\
\hline \multicolumn{14}{|l|}{ Political Groups (US Only) } \\
\hline US: Republican & 0.7 & $0.65-0.75$ & 0 & -0.01 & $-0.12-0.10$ & 0.85 & 0.18 & $0.08-0.27$ & 0 & 0.09 & $0.01-0.17$ & 0.02 & 376 \\
\hline US: Democrat & 0.78 & $0.74-0.83$ & 0 & 0.15 & $0.03-0.27$ & 0.01 & 0.25 & $0.15-0.36$ & 0 & 0.21 & $0.12-0.30$ & 0 & 315 \\
\hline US: Indep/Other & 0.75 & $0.71-0.80$ & 0 & 0.03 & $-0.09-0.14$ & 0.65 & 0.23 & $0.14-0.33$ & 0 & 0.16 & $0.07-0.24$ & 0 & 419 \\
\hline \multicolumn{14}{|l|}{ Robustness Checks } \\
\hline Correctly answered all comprehension questions & 0.86 & $0.85-0.88$ & 0 & 0.17 & $0.11-0.22$ & 0 & 0.37 & $0.33-0.42$ & 0 & 0.23 & $0.19-0.26$ & 0 & 1,529 \\
\hline No college degree & 0.77 & $0.75-0.79$ & 0 & 0.15 & $0.09-0.20$ & 0 & 0.28 & $0.23-0.33$ & 0 & 0.18 & $0.14-0.23$ & 0 & 1,546 \\
\hline
\end{tabular}

Table S5 shows the results are consistent across parameters we used in describing the challenge and standard trials.

Table S5: Study 1 - Main Results, By Randomized Description of Trial Designs

\begin{tabular}{|c|c|c|c|c|c|c|c|c|c|c|c|c|c|}
\hline & \multicolumn{3}{|c|}{$\begin{array}{c}\text { Prefers Scientists } \\
\text { Conduct Challenge } \\
\text { Study }(0 / 1)\end{array}$} & \multicolumn{3}{|c|}{$\begin{array}{l}\text { How Ethical (1-4): } \\
\text { Challenge Minus } \\
\text { Standard }\end{array}$} & \multicolumn{3}{|c|}{$\begin{array}{c}\text { How Scientifically } \\
\text { Valid (1-4): Challenge } \\
\text { Minus Standard }\end{array}$} & \multicolumn{3}{|c|}{$\begin{array}{l}\text { Would Take Vaccine } \\
(1-4): \text { Challenge Minus } \\
\text { Standard }\end{array}$} & \multirow[b]{2}{*}{$\mathrm{N}$} \\
\hline & Mean & $95 \% \mathrm{CI}$ & $\mathrm{p}$ & Mean & $95 \% \mathrm{CI}$ & $\mathrm{p}$ & Mean & $95 \% \mathrm{CI}$ & $\mathrm{p}$ & Mean & $95 \% \mathrm{CI}$ & $\mathrm{p}$ & \\
\hline All participants & 0.75 & $0.73-0.76$ & 0 & 0.06 & $0.02-0.10$ & 0.01 & 0.23 & $0.20-0.27$ & 0 & 0.14 & $0.11-0.17$ & 0 & 2,988 \\
\hline \multicolumn{14}{|c|}{ Speed of Standard Trial; How Many Months Challenge Accelerates Timeline } \\
\hline 12; Challenge 2 Mo Faster & 0.73 & $0.69-0.77$ & 0 & 0.01 & $-0.09-0.11$ & 0.82 & 0.23 & $0.15-0.31$ & 0 & 0.1 & $0.02-0.17$ & 0.01 & 513 \\
\hline 12; Challenge 4 Mo Faster & 0.75 & $0.72-0.79$ & 0 & 0.1 & $-0.01-0.21$ & 0.07 & 0.27 & $0.18-0.36$ & 0 & 0.17 & $0.09-0.24$ & 0 & 477 \\
\hline 12 ; Challenge 6 Mo Faster & 0.78 & $0.74-0.81$ & 0 & 0.07 & $-0.03-0.17$ & 0.19 & 0.29 & $0.21-0.37$ & 0 & 0.17 & $0.10-0.25$ & 0 & 509 \\
\hline 18; Challenge 2 Mo Faster & 0.72 & $0.68-0.76$ & 0 & 0.04 & $-0.06-0.14$ & 0.42 & 0.15 & $0.06-0.24$ & 0 & 0.13 & $0.05-0.21$ & 0 & 466 \\
\hline 18; Challenge 4 Mo Faster & 0.76 & $0.73-0.80$ & 0 & 0.14 & $0.04-0.24$ & 0.01 & 0.3 & $0.22-0.38$ & 0 & 0.13 & $0.06-0.20$ & 0 & 483 \\
\hline 18; Challenge 6 Mo Faster & 0.74 & $0.70-0.77$ & 0 & -0.01 & $-0.10-0.09$ & 0.88 & 0.16 & $0.08-0.23$ & 0 & 0.17 & $0.10-0.23$ & 0 & 540 \\
\hline \multicolumn{14}{|c|}{$\%$ of Placebo Subjects in Standard Trial Who Get Sick, Die } \\
\hline $2 \%$ Sick; $0.5 \%$ of Sick Die & 0.71 & $0.67-0.75$ & 0 & -0.16 & $-0.25--0.06$ & 0 & 0.21 & $0.13-0.29$ & 0 & 0.06 & $0.00-0.13$ & 0.05 & 500 \\
\hline $2 \%$ Sick; $1 \%$ of Sick Die & 0.75 & $0.71-0.78$ & 0 & 0.02 & $-0.08-0.12$ & 0.68 & 0.23 & $0.15-0.31$ & 0 & 0.17 & $0.10-0.24$ & 0 & 515 \\
\hline $5 \%$ Sick; $0.5 \%$ of Sick Die & 0.75 & $0.71-0.79$ & 0 & 0.12 & $0.02-0.23$ & 0.02 & 0.25 & $0.17-0.33$ & 0 & 0.19 & $0.12-0.26$ & 0 & 488 \\
\hline $5 \%$ Sick; $1 \%$ of Sick Die & 0.76 & $0.72-0.80$ & 0 & 0.18 & $0.07-0.28$ & 0 & 0.26 & $0.18-0.35$ & 0 & 0.16 & $0.09-0.24$ & 0 & 488 \\
\hline $20 \%$ Sick; $0.5 \%$ of Sick Die & 0.73 & $0.69-0.77$ & 0 & 0.11 & $0.00-0.21$ & 0.04 & 0.21 & $0.12-0.30$ & 0 & 0.12 & $0.04-0.20$ & 0.01 & 476 \\
\hline $20 \%$ Sick; $1 \%$ of Sick Die & 0.78 & $0.74-0.82$ & 0 & 0.08 & $-0.01-0.18$ & 0.09 & 0.23 & $0.15-0.31$ & 0 & 0.17 & $0.09-0.24$ & 0 & 521 \\
\hline \multicolumn{14}{|l|}{ Size of Standard Trial } \\
\hline Standard Trial N $=3000$ & 0.74 & $0.70-0.77$ & 0 & 0.01 & $-0.08-0.10$ & 0.86 & 0.27 & $0.20-0.35$ & 0 & 0.1 & $0.03-0.17$ & 0.01 & 605 \\
\hline Standard Trial $N=5000$ & 0.77 & $0.73-0.80$ & 0 & 0.08 & $-0.02-0.17$ & 0.1 & 0.24 & $0.17-0.31$ & 0 & 0.16 & $0.10-0.23$ & 0 & 620 \\
\hline Standard Trial $\mathrm{N}=7000$ & 0.75 & $0.71-0.78$ & 0 & 0.05 & $-0.04-0.14$ & 0.3 & 0.21 & $0.14-0.29$ & 0 & 0.16 & $0.10-0.23$ & 0 & 596 \\
\hline Standard Trial N $=9000$ & 0.75 & $0.71-0.78$ & 0 & 0.08 & $-0.01-0.18$ & 0.08 & 0.2 & $0.12-0.28$ & 0 & 0.14 & $0.07-0.20$ & 0 & 570 \\
\hline Standard Trial N $=11000$ & 0.73 & $0.69-0.77$ & 0 & 0.07 & $-0.02-0.17$ & 0.12 & 0.23 & $0.16-0.31$ & 0 & 0.16 & $0.10-0.23$ & 0 & 597 \\
\hline
\end{tabular}

The only case in which participants rate the standard trial as more ethical than the challenge trial is for participants who saw a version of the trial summary where the proportion of subjects in the standard trial who are sick was randomized to the lowest $(2 \%)$ and the proportion of those who get sick who die was randomized to the lowest $(0.5 \%)$. Respondents' ratings of the standard trial as more ethical than the challenge trial in this case is driven by participants rating the standard trials as more ethical, not the challenge trial as less ethical, than participants who were randomized to other scenarios. Moreover, it is driven by participants who saw smaller standard trials (Ns of 3,000 or 5,000); in these cases, no participants in the standard trials 
die, and fewer participants catch coronavirus than in the challenge trial. It is possible that participants recognized an ethical advantage of the standard trial in this case. However, even these participants still rated the challenge trial similarly ethical as other participants and still favored the challenge trial on average.

\section{Multivariate Regression Results}

Figure S2 also visualizes coefficients from a multivariate regression predicting preference for the challenge trial. Variables denoted with (Std.) have been rescaled to standard deviation 1. Note that these coefficients should be interpreted as descriptive, not causal, and that all coefficients are calculated holding constant the other variables shown. The intercept of the regression is 0.78 and the omitted base categories in the regressions are: United States; age 18-24; male; no college degree; employment one of homemaker, student, unable to work, or unemployed since before the coronavirus pandemic; the challenge trial being study A; and average values of the rescaled variables. The coefficients below represent estimated differences from these base categories, holding constant on the other variables in the model.

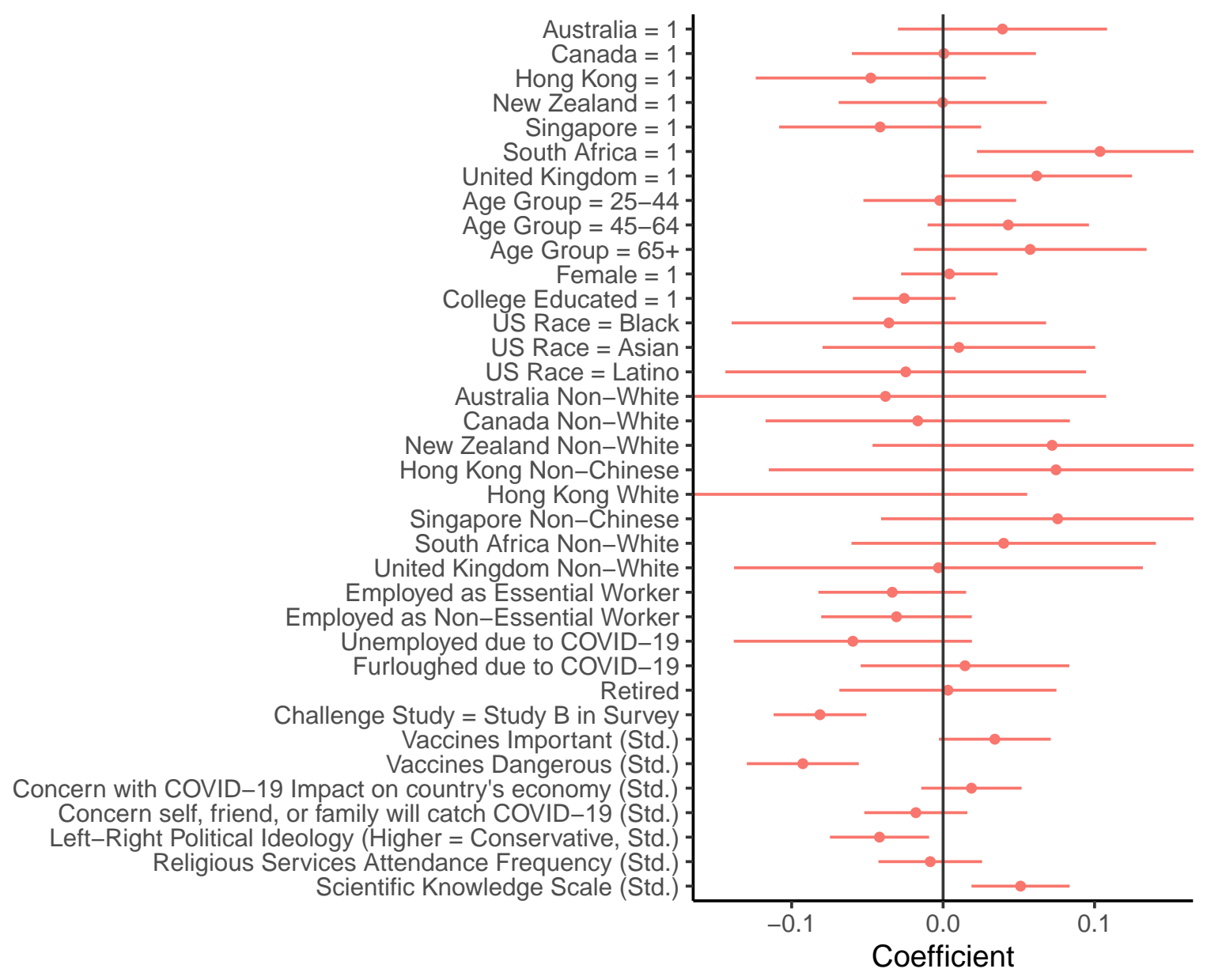

Figure S2: Predictors of Preference for Challenge Trial

Figure S3 shows the results of a multivariate regression regressing the same variables as above on a binary indicator for whether respondents got all the comprehension questions about the challenge study correct. Gender, age, views towards vaccines, and scientific knowledge generally predict comprehension. This regression was not pre-registered. 


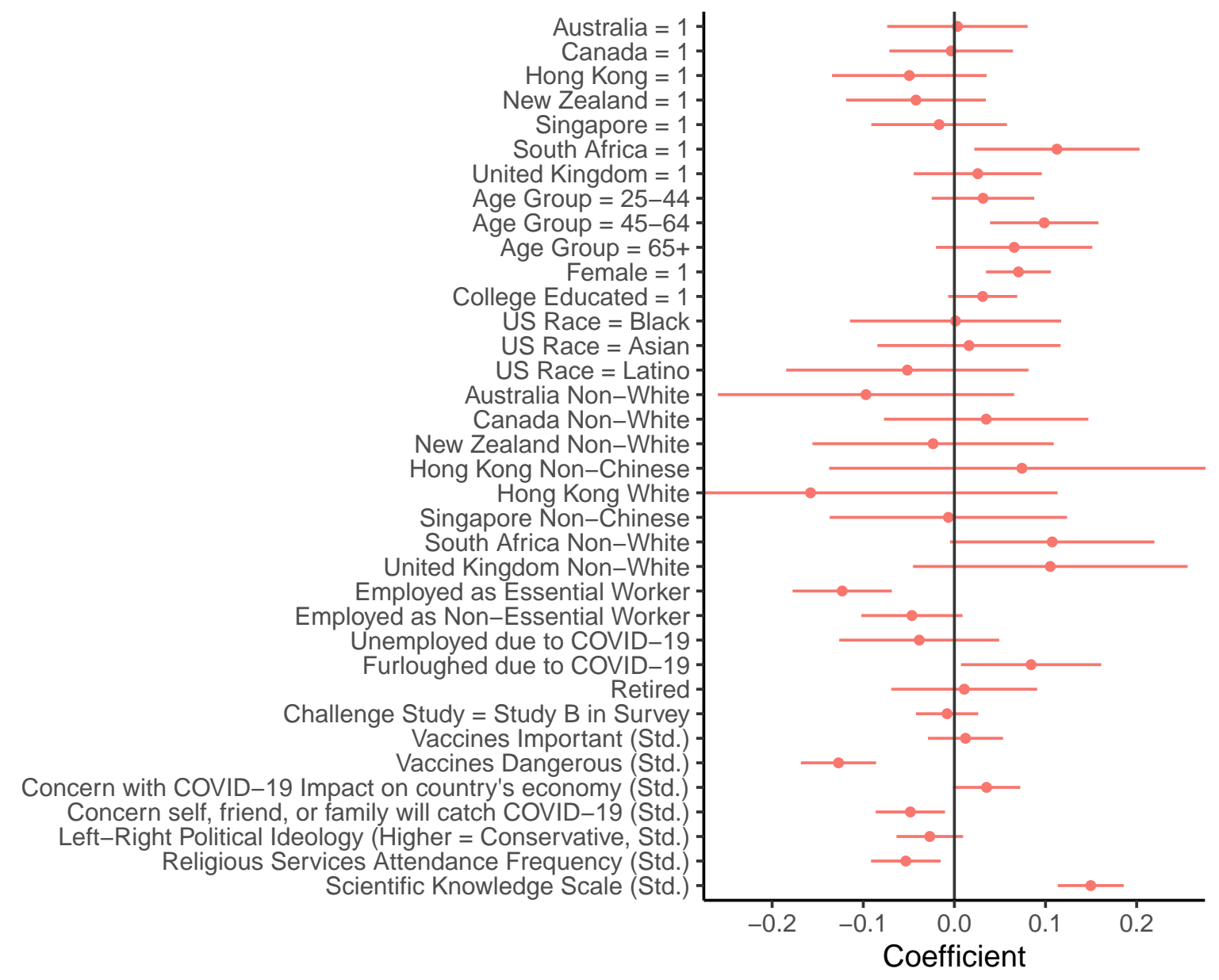

Figure S3: Predictors of Answering Scientific Knowledge Questions Correctly for Challenge Trial 


\section{Sensitivity Analysis}

We also conduct a sensitivity analysis to determine how unrepresentative our sample would need to be in order to alter our conclusions. In particular, we compute [5]'s $\gamma$ for the proportion that prefer the challenge study as 2.78 at a p-value of 0.10 . This means that our statistical significance for the null hypothesis that challenge trials are equally preferred to standard trials would only no longer reach significance at the 0.10 level were individuals who do not prefer challenge trials to be 2.78 times less likely than individuals who prefer challenge trials to be selected for the survey. For comparison, it is very unusual in social science studies to observe a $\gamma$ value greater than $2[4]$. 


\section{Study 2: Integrated Trial}

\section{Vaccine Study Design Description}

After the preamble quoted earlier, participants were shown a table that looks like the example in Figure S4. All of the highlighted elements were randomized. We did not allow participants to move on from the page describing the trial design until at least 60 seconds had gone by.

\begin{tabular}{|c|c|c|c|}
\hline Name & Study A & Study B & Key Differences \\
\hline $\begin{array}{c}\text { Study } \\
\text { procedures }\end{array}$ & $\begin{array}{l}\text { 1. Recruit } 9,000 \text { healthy } \\
\text { volunteers to participate. } \\
2 \text {. Give a few hundred } \\
\text { participants the vaccine every } \\
\text { week. Stop the study and stop } \\
\text { giving participants the vaccine if } \\
\text { it is found to be unsafe or } \\
\text { unlikely to work. } \\
\text { 3. If the vaccine is safe, } \\
\text { eventually } 4,500 \text { participants } \\
\text { will get the vaccine. Another } \\
4,500 \text { will get a placebo. }\end{array}$ & $\begin{array}{l}\text { 1. In a preliminary study, recruit } \\
200 \text { healthy people who volunteer } \\
\text { to receive the vaccine. After a } \\
\text { month, check whether the vaccine } \\
\text { has a good chance of working and } \\
\text { gather more data on how safe it is. } \\
\text { If the vaccine is found to be } \\
\text { unsafe or is shown to be unlikely } \\
\text { to work, the study stops here. } \\
\text { 2. Recruit } 9,000 \text { more healthy } \\
\text { volunteers to participate. } \\
\text { 3. Give } 4,500 \text { participants the } \\
\text { vaccine. Another } 4,500 \text { get a } \\
\text { placebo. }\end{array}$ & $\begin{array}{l}\text { - Study B first takes a few } \\
\text { months to determine whether } \\
\text { the vaccine has a good chance } \\
\text { of working and further checks } \\
\text { whether it is safe before } \\
\text { continuing. Study } \\
\text { A immediately starts } \\
\text { investigating whether the } \\
\text { vaccine actually works, } \\
\text { checking to see whether the } \\
\text { vaccine is safe and has a good } \\
\text { chance of working as it gets } \\
\text { started. }\end{array}$ \\
\hline $\begin{array}{c}\text { Risks to } \\
\text { study } \\
\text { participants }\end{array}$ & $\begin{array}{l}\text { - While unlikely, if it turns out } \\
\text { the vaccine was not safe, } \\
\text { approximately } 250 \text { people would } \\
\text { have received the unsafe vaccine } \\
\text { before scientists realized it was } \\
\text { unsafe and could have negative } \\
\text { side effects. }\end{array}$ & $\begin{array}{l}\text { - If it turns out the vaccine was } \\
\text { not safe, } 200 \text { people would have } \\
\text { received the unsafe vaccine and } \\
\text { could have negative side effects. }\end{array}$ & $\begin{array}{l}\text { - While unlikely, if the vaccine } \\
\text { is not safe, Study A would } \\
\text { expose } 50 \text { additional people to } \\
\text { it before the problem was } \\
\text { found. }\end{array}$ \\
\hline $\begin{array}{l}\text { Expected } \\
\text { time until } \\
\text { vaccine } \\
\text { ready }\end{array}$ & $\begin{array}{l}\text { If the vaccine works, it would } \\
\text { start being distributed widely } \\
\text { starting in } 10 \text { months, March } \\
2021 .\end{array}$ & $\begin{array}{l}\text { If the vaccine works, it would } \\
\text { start being distributed widely in } \\
12 \text { months, May } 2021 .\end{array}$ & $\begin{array}{l}\text { - If the vaccine works, Study } \\
\text { A would allow it to be ready } 2 \\
\text { months sooner. }\end{array}$ \\
\hline $\begin{array}{l}\text { Benefits to } \\
\text { society, if } \\
\text { the vaccine } \\
\text { works }\end{array}$ & $\begin{array}{l}\text { During the } 10 \text { months between } \\
\text { now and when the vaccine is } \\
\text { ready, it is estimated that: } \\
\cdot 2,000,000 \text { people will die from } \\
\text { coronavirus. } \\
\text { - Millions of people will remain } \\
\text { out of work. } \\
\text { However, once the vaccine is } \\
\text { ready and starts reaching all } \\
\text { those who need it in March } \\
\text { 2021: } \\
\text { - Very few people will die of } \\
\text { coronavirus any more. } \\
\text { - Daily life and the economy will } \\
\text { return to normal. }\end{array}$ & $\begin{array}{l}\text { During the } 12 \text { months between } \\
\text { now and when the vaccine is } \\
\text { ready, it is estimated that: } \\
\text { - } 2,400,000 \text { people will die from } \\
\text { coronavirus. } \\
\text { - Millions of people will remain } \\
\text { out of work. } \\
\text { However, once the vaccine is } \\
\text { ready and starts reaching all those } \\
\text { who need it in May } 2021 \text { : } \\
\text { - Very few people will die of } \\
\text { coronavirus any more. } \\
\text { - Daily life and the economy will } \\
\text { return to normal. }\end{array}$ & $\begin{array}{l}\text { - With Study A, } 400,000 \text { lives } \\
\text { are saved. } \\
\text { - With Study A, people can } \\
\text { return to work and daily life can } \\
\text { return to normal } 2 \text { months } \\
\text { sooner. }\end{array}$ \\
\hline
\end{tabular}

Figure S4: Example Stimulus, Study 2 (Study A is Integrated Trial in this example)

The example in Figure S4 shows the results of one particular randomization. All the highlighted numbers in the example were randomized, as detailed below. (These highlights did not appear to survey respondents.) In the below, the bolded numbers correspond with the numbers in the example shown in Figure S4. We 
randomized these parameters given uncertainty about how particular vaccine trials might be conducted, to ensure our findings were not sensitive to any of these parameters.

The following elements could have been randomized. The bold corresponds to the example shown in Figure S4.

- Standard Design Trial N (3,000; 5,000; 7,000; 9,000; 11,000)

$-\mathrm{N}$ in each condition is calculated as half of this number.

- How long the Standard Design takes to get a vaccine ready: 12 or 18 months.

- The date (e.g., May 2021), is calculated automatically based on the current date. The number of people in society who die (e.g., $\mathbf{2 , 4 0 0 , 0 0 0}$ ) is calculated by multiplying the number of months until a vaccine is ready by 200,000. 200,000 is a fixed variable for both study designs. We selected 200,000 deaths per month as that is approximately the number of COVID-19 deaths in April 2020, and so therefore represents a likely conservative estimate of likely COVID-19 deaths per month in the months ahead.

- How much faster the Integrated Design is: 2, 4, or 6 months faster

- The date the vaccine is ready if an integrated trial is used is the date above minus this number.

- How many people in the Integrated Design are exposed to the vaccine before it stops, in the case that the vaccine is found to be unsafe $(\mathbf{2 5 0} ; 400 ; 1,000)$

- Which design is described as "Study A" or "Study B". Whichever study was described as "Study A" always was shown in the first column.

In the "Key Differences" column, the differences are taken based on the randomizations from Studies A and B. Table S9, presented later, shows the results are consistent across parameters we used in describing the integrated and standard trials.

After reading this table, we then provided participants with a short summary of the key points. In the example in Figure S4, this would look as follows:

\section{Summary:}

- Study A:

- Scientists first conduct a study with fewer participants to be extra sure the vaccine is safe and likely to work before continuing.

- It takes longer for the vaccine to be ready, so more people die of coronavirus in society generally.

- Study B:

- Scientists give a larger number of participants the vaccine sooner, collecting data as they go to be extra sure the vaccine is safe and has a good chance of working.

- There is a small chance that the vaccine is unsafe or won't work, in which case 250 more people would have received this ineffective or unsafe vaccine.

- The vaccine is ready sooner, so fewer people die of coronavirus in society generally.

Whichever study was randomized to be Study A is always shown first.

Respondents then answered the primary outcome measures. Next, on a separate page, they were asked to answer scenario comprehension questions to ensure they understood the studies. Respondents could not return to the table when answering the comprehension questions. Below we describe the outcome measures and comprehension questions in more detail.

\section{Scenario Comprehension Outcomes}

We asked the following scenario comprehension questions: 
- If the vaccine works, which of the two studies we asked about would result in the vaccine being approved and widely available sooner?

- If the vaccine works, which of the two studies we asked about would result in more people in society generally dying of coronavirus?

- Which of the two studies we asked about involves doing additional safety testing on a smaller group first?

Responses are coded as " 1 " if the participant provided the correct answer and " 0 " if they coded the incorrect answer. Table S6 reports the average rate of correct answers overall and by geography. We also show the results for the US when weighting the sample to the 2019 US Census population estimates for gender, age, race, and education, as described above. We again separately report results for self-identified whites and non-whites in Hong Kong for the reasons described above.

The $p$-value is from one-sample $t$-tests testing the null hypothesis that the rate of correct answers is equal to 0.5 , which is what would be expected from random guessing.

The vast majority of participants understood the scenarios. Later, in Table S8, we show that support for the integrated trial is strongest for those who correctly answered all the scenario comprehension.

Table S6: Study 2 - Proportions Correctly Answering Scenario Comprehension Questions

\begin{tabular}{|c|c|c|c|c|c|c|c|c|c|c|}
\hline & \multicolumn{3}{|c|}{$\begin{array}{c}\text { Vaccine Is Ready } \\
\text { Faster With Integrated } \\
\text { Correct }(0 / 1)\end{array}$} & \multicolumn{3}{|c|}{$\begin{array}{l}\text { More People in Society } \\
\text { Die In Which Study } \\
\text { Correct }(0 / 1)\end{array}$} & \multicolumn{3}{|c|}{$\begin{array}{c}\text { Standard Involves } \\
\text { Additional Testing } \\
\text { Correct }(0 / 1) \\
\end{array}$} & \multirow[b]{2}{*}{$\mathrm{N}$} \\
\hline & Mean & $95 \% \mathrm{CI}$ & $\mathrm{p}$ & Mean & $95 \%$ CI & $\mathrm{p}$ & Mean & $95 \%$ CI & $\mathrm{p}$ & \\
\hline All Participants & 0.85 & $0.83-0.86$ & 0 & 0.81 & $0.79-0.82$ & 0 & 0.75 & $0.73-0.76$ & 0 & 2,932 \\
\hline AUS & 0.84 & $0.79-0.88$ & 0 & 0.81 & $0.76-0.85$ & 0 & 0.76 & $0.71-0.81$ & 0 & 278 \\
\hline CAN & 0.86 & $0.82-0.90$ & 0 & 0.79 & $0.75-0.84$ & 0 & 0.75 & $0.71-0.80$ & 0 & 341 \\
\hline HK (Non-White) & 0.76 & $0.70-0.82$ & 0 & 0.73 & $0.67-0.79$ & 0 & 0.64 & $0.58-0.71$ & 0 & 194 \\
\hline HK (White) & 0.55 & $0.31-0.79$ & 0.67 & 0.65 & $0.42-0.88$ & 0.19 & 0.35 & $0.12-0.58$ & 0.19 & 20 \\
\hline $\mathrm{NZ}$ & 0.86 & $0.81-0.90$ & 0 & 0.82 & $0.77-0.87$ & 0 & 0.78 & $0.73-0.83$ & 0 & 243 \\
\hline SA & 0.93 & $0.90-0.96$ & 0 & 0.87 & $0.83-0.91$ & 0 & 0.78 & $0.73-0.83$ & 0 & 263 \\
\hline$\overline{S G}$ & 0.79 & $0.74-0.84$ & 0 & 0.8 & $0.75-0.85$ & 0 & 0.69 & $0.63-0.75$ & 0 & 239 \\
\hline UK & 0.88 & $0.84-0.92$ & 0 & 0.83 & $0.79-0.88$ & 0 & 0.79 & $0.74-0.84$ & 0 & 284 \\
\hline US & 0.85 & $0.83-0.87$ & 0 & 0.79 & $0.77-0.82$ & 0 & 0.76 & $0.74-0.79$ & 0 & 1,070 \\
\hline US, Weighted & 0.85 & $0.83-0.87$ & 0 & 0.8 & $0.78-0.83$ & 0 & 0.76 & $0.73-0.78$ & 0 & 1,070 \\
\hline
\end{tabular}

\section{Primary and Secondary Outcomes}

We asked the following outcome measures:

- If you had to choose, which study would you rather have scientists conduct?

- How ethical do you think the studies are?

- How scientifically valid do you think the studies are?

- If the study found the vaccine worked and it was then approved by the government, how likely would you be to take the vaccine to protect yourself from coronavirus?

We pre-specified the first as a primary outcome and the difference between the ratings for the integrated and standard trial designs as secondary outcomes.

Table S7 shows the overall results and results by geography on each of these dependent variables. We again separately report results for self-identified whites and non-whites in Hong Kong for the reasons described above. The $p$-value for the primary outcome is from one-sample $t$-tests testing the null hypothesis that an equal number of participants selecting the integrated and standard trial designs (0.5). For the other outcomes, the $p$-values are from one-sample $t$-tests testing the null hypothesis that the mean is equal to 0 , meaning 
there is no difference respondents' ratings of the integrated trial and standard design on the outcome measure at hand.

Even though participants on average are more likely to select the integrated trial, the averages of the secondary outcomes are slightly higher for the standard design because those who select the standard design gave more extreme responses. For example, participants who selected the integrated trial rated the integrated trial as equally ethical (only 0.01 scale points less ethical on average), whereas those who favored the standard trial rated the integrated trial as 0.62 scale points less ethical on average. However, $58 \%$ of respondents who did not prefer the integrated trial still said they thought the integrated trial was "probably" or"definitely ethical."

Table S7: Study 2 - Main Results, All Participants and by Participant Geography

\begin{tabular}{|c|c|c|c|c|c|c|c|c|c|c|c|c|c|}
\hline & \multicolumn{3}{|c|}{$\begin{array}{l}\text { Prefers Scientists } \\
\text { Conduct Integrated } \\
\text { Study }(0 / 1)\end{array}$} & \multicolumn{3}{|c|}{$\begin{array}{c}\text { How Ethical (1-4): } \\
\text { Integrated Minus } \\
\text { Standard }\end{array}$} & \multicolumn{3}{|c|}{$\begin{array}{l}\text { How Scientifically } \\
\text { Valid (1-4): } \\
\text { Integrated Minus } \\
\text { Standard } \\
\end{array}$} & \multicolumn{3}{|c|}{$\begin{array}{c}\text { Would Take Vaccine } \\
\text { (1-4): Integrated } \\
\text { Minus Standard }\end{array}$} & \multirow[b]{2}{*}{$\mathrm{N}$} \\
\hline & Mean & $95 \% \mathrm{CI}$ & $\mathrm{p}$ & Mean & $95 \% \mathrm{CI}$ & $\mathrm{p}$ & Mean & $95 \% \mathrm{CI}$ & $\mathrm{p}$ & Mean & $95 \% \mathrm{CI}$ & $\mathrm{p}$ & \\
\hline All Participants & 0.63 & $0.61-0.65$ & 0 & -0.24 & $-0.27--0.21$ & 0 & -0.05 & $-0.07--0.03$ & 0 & -0.05 & $-0.08--0.03$ & 0 & 2,932 \\
\hline AUS & 0.64 & $0.58-0.69$ & 0 & -0.27 & $-0.35--0.19$ & 0 & -0.05 & $-0.12-0.02$ & 0.18 & -0.06 & $-0.14-0.03$ & 0.19 & 278 \\
\hline $\mathrm{CAN}$ & 0.66 & $0.61-0.71$ & 0 & -0.24 & $-0.32--0.16$ & 0 & -0.05 & $-0.11-0.02$ & 0.15 & -0.04 & $-0.10-0.03$ & 0.3 & 341 \\
\hline HK (Non-White) & 0.52 & $0.44-0.59$ & 0.67 & -0.29 & $-0.43--0.15$ & 0 & -0.05 & $-0.16-0.06$ & 0.36 & -0.11 & $-0.24-0.02$ & 0.1 & 194 \\
\hline HK (White) & 0.25 & $0.04-0.46$ & 0.02 & -0.4 & $-0.72--0.08$ & 0.02 & 0.05 & $-0.49-0.59$ & 0.85 & -0.4 & $-0.87-0.07$ & 0.09 & 20 \\
\hline $\mathrm{NZ}$ & 0.6 & $0.53-0.66$ & 0 & -0.15 & $-0.25--0.05$ & 0 & -0.03 & $-0.11-0.05$ & 0.47 & -0.04 & $-0.12-0.05$ & 0.38 & 243 \\
\hline SA & 0.66 & $0.60-0.72$ & 0 & -0.26 & $-0.37--0.14$ & 0 & -0.06 & $-0.15-0.03$ & 0.17 & -0.02 & $-0.12-0.07$ & 0.64 & 263 \\
\hline SG & 0.5 & $0.44-0.57$ & 0.95 & -0.37 & $-0.49--0.25$ & 0 & -0.05 & $-0.15-0.04$ & 0.28 & -0.11 & $-0.22-0.00$ & 0.06 & 239 \\
\hline UK & 0.7 & $0.65-0.75$ & 0 & -0.27 & $-0.36--0.18$ & 0 & -0.04 & $-0.10-0.03$ & 0.24 & -0.04 & $-0.11-0.04$ & 0.36 & 284 \\
\hline US & 0.65 & $0.62-0.68$ & 0 & -0.18 & $-0.23--0.14$ & 0 & -0.05 & $-0.09--0.01$ & 0.01 & -0.02 & $-0.06-0.02$ & 0.38 & 1,070 \\
\hline US, Weighted & 0.65 & $0.62-0.68$ & 0 & -0.19 & $-0.23--0.14$ & 0 & -0.06 & $-0.09--0.02$ & 0.01 & -0.05 & $-0.09--0.00$ & 0.03 & 1,070 \\
\hline
\end{tabular}

Table S8 shows that the results are similar across a variety of vulnerable populations, those who answered all the scenario comprehension questions correctly, and various politically relevant subgroups. As described above, we also examine a racial subgroup of non-white in Australia, Canada, New Zealand, the United Kingdom, and the United States, and as both non-Chinese and non-white in Hong Kong and Singapore. The not college educated subgroup was not pre-specified, but is shown to demonstrate that our conclusions are not driven by the fact that our sample is slightly more educated than the general population.

Table S8: Study 2 - Main Results By Demographic Groups

\begin{tabular}{|c|c|c|c|c|c|c|c|c|c|c|c|c|c|}
\hline & \multicolumn{3}{|c|}{$\begin{array}{l}\text { Prefers Scientists } \\
\text { Conduct Integrated } \\
\text { Study }(0 / 1)\end{array}$} & \multicolumn{3}{|c|}{$\begin{array}{c}\text { How Ethical (1-4): } \\
\text { Integrated Minus } \\
\text { Standard }\end{array}$} & \multicolumn{3}{|c|}{$\begin{array}{c}\text { How Scientifically } \\
\text { Valid (1-4): } \\
\text { Integrated Minus } \\
\text { Standard }\end{array}$} & \multicolumn{3}{|c|}{$\begin{array}{l}\text { Would Take Vaccine } \\
\text { (1-4): Integrated } \\
\text { Minus Standard }\end{array}$} & \multirow[b]{2}{*}{$\mathrm{N}$} \\
\hline & Mean & $95 \% \mathrm{CI}$ & $\mathrm{p}$ & Mean & $95 \% \mathrm{CI}$ & $\mathrm{p}$ & Mean & $95 \% \mathrm{CI}$ & $\mathrm{p}$ & Mean & $95 \% \mathrm{CI}$ & $\mathrm{p}$ & \\
\hline All Participants & 0.63 & $0.61-0.65$ & 0 & -0.24 & $-0.27--0.21$ & 0 & -0.05 & $-0.07--0.03$ & 0 & -0.05 & $-0.08--0.03$ & 0 & 2,932 \\
\hline \multicolumn{14}{|l|}{ Vulnerable Populations } \\
\hline Age 65+ & 0.74 & $0.70-0.78$ & 0 & -0.12 & \begin{tabular}{|c|c|}
$-0.18--0.06$ \\
-18
\end{tabular} & 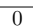 & -0.01 & $-0.06-0.04$ & 0.67 & 0.04 & $-0.02-0.10$ & 0.17 & 507 \\
\hline Essential Worker & 0.57 & $0.54-0.60$ & 0 & -0.23 & $-0.28--0.17$ & 0 & -0.07 & $-0.12--0.02$ & 0 & -0.04 & $-0.10-0.01$ & 0.1 & 880 \\
\hline Non-White (In HK \& SG, Non-Chinese) & 0.55 & $0.52-0.59$ & 0 & -0.29 & $-0.35--0.22$ & 0 & -0.09 & $-0.15--0.03$ & 0 & -0.1 & $-0.17--0.04$ & 0 & 728 \\
\hline US: County cases $>$ median & 0.64 & $0.60-0.68$ & 0 & -0.19 & $-0.26--0.13$ & 0 & -0.06 & $-0.12--0.00$ & 0.04 & -0.04 & $-0.10-0.02$ & 0.21 & 550 \\
\hline \multicolumn{14}{|l|}{ Political Groups (US Only) } \\
\hline US: Republican & \begin{tabular}{|l|}
0.68 \\
\end{tabular} & $0.63-0.73$ & \begin{tabular}{|l|}
0 \\
0
\end{tabular} & -0.14 & \begin{tabular}{|l|l|}
$-0.21--0.06$ \\
\end{tabular} & 0 & -0.03 & $-0.09-0.04$ & 0.43 & -0.05 & $-0.12-0.02$ & 0.19 & 358 \\
\hline US: Democrat & 0.63 & $0.58-0.68$ & 0 & -0.15 & $-0.23--0.07$ & 0 & -0.04 & $-0.11-0.03$ & 0.26 & -0.01 & $-0.07-0.06$ & 0.85 & 331 \\
\hline US: Indep/Other & 0.65 & $0.60-0.69$ & 0 & -0.27 & $-0.35--0.19$ & 0 & -0.1 & $-0.17--0.03$ & 0.01 & -0.08 & $-0.15--0.00$ & 0.04 & 381 \\
\hline \multicolumn{14}{|l|}{ Robustness Checks } \\
\hline Correctly answered all comprehension questions & 0.68 & $0.66-0.70$ & \begin{tabular}{|l|}
0 \\
\end{tabular} & -0.29 & \begin{tabular}{|l}
$-0.33--0.26$ \\
\end{tabular} & 0 & -0.08 & $-0.10--0.05$ & 0 & -0.05 & \begin{tabular}{|c|}
$-0.08--0.02$ \\
\end{tabular} & 0 & 1,745 \\
\hline No college degree & 0.64 & $0.61-0.66$ & 0 & -0.2 & $-0.24--0.15$ & 0 & -0.03 & $-0.06-0.00$ & 0.08 & -0.04 & \begin{tabular}{|c|}
$-0.07-0.00$ \\
\end{tabular} & 0.05 & 1,496 \\
\hline
\end{tabular}

Table S5 shows the results are consistent across parameters we used in describing the integrated and standard trials. Unsurprisingly, respondents were slightly less likely to favor the integrated design when greater numbers of study participants receive the vaccine before a safety or immunogenicity problem with the vaccine could be detected. 
Table S9: Study 2 - Main Results By Randomized Description of Trial Designs

\begin{tabular}{|c|c|c|c|c|c|c|c|c|c|c|c|c|c|}
\hline & \multicolumn{3}{|c|}{$\begin{array}{l}\text { Prefers Scientists } \\
\text { Conduct Integrated } \\
\text { Study }(0 / 1)\end{array}$} & \multicolumn{3}{|c|}{$\begin{array}{l}\text { How Ethical (1-4): } \\
\text { Integrated Minus } \\
\text { Standard }\end{array}$} & \multicolumn{3}{|c|}{$\begin{array}{l}\text { How Scientifically } \\
\text { Valid (1-4): } \\
\text { Integrated Minus } \\
\text { Standard }\end{array}$} & \multicolumn{3}{|c|}{$\begin{array}{c}\text { Would Take Vaccine } \\
\text { (1-4): Integrated } \\
\text { Minus Standard }\end{array}$} & \multirow[b]{2}{*}{$\mathrm{N}$} \\
\hline & Mean & $95 \%$ CI & $\mathrm{p}$ & Mean & $95 \% \mathrm{CI}$ & $\mathrm{p}$ & Mean & $95 \%$ CI & $\mathrm{p}$ & Mean & $95 \%$ CI & $\mathrm{p}$ & \\
\hline All Participants & 0.63 & $0.61-0.65$ & 0 & -0.24 & $-0.27--0.21$ & 0 & -0.05 & $-0.07--0.03$ & 0 & -0.05 & $-0.08--0.03$ & 0 & 2,932 \\
\hline \multicolumn{14}{|c|}{ Speed of Standard Trial; How Many Months Integrated Accelerates Timeline } \\
\hline 12; Integrated 2 Mo Faster & 0.57 & $0.53-0.61$ & 0 & -0.23 & $-0.30--0.16$ & 0 & -0.04 & $-0.09-0.01$ & 0.15 & -0.13 & $-0.19--0.06$ & 0 & 501 \\
\hline 12; Integrated 4 Mo Faster & 0.63 & $0.59-0.68$ & 0 & -0.25 & $-0.32--0.18$ & 0 & -0.03 & $-0.08-0.03$ & 0.36 & -0.07 & $-0.13--0.00$ & 0.04 & 495 \\
\hline 12; Integrated 6 Mo Faster & 0.69 & $0.65-0.73$ & 0 & -0.21 & $-0.29--0.14$ & 0 & -0.04 & $-0.10-0.02$ & 0.16 & -0.02 & $-0.08-0.04$ & 0.55 & 509 \\
\hline 18; Integrated 2 Mo Faster & 0.58 & $0.53-0.62$ & 0 & -0.27 & $-0.34--0.19$ & 0 & -0.05 & $-0.11-0.02$ & 0.14 & -0.04 & $-0.11-0.04$ & 0.33 & 451 \\
\hline 18; Integrated 4 Mo Faster & 0.64 & $0.60-0.68$ & 0 & -0.25 & $-0.32--0.18$ & 0 & -0.03 & $-0.09-0.03$ & 0.33 & -0.04 & $-0.10-0.02$ & 0.19 & 490 \\
\hline 18; Integrated 6 Mo Faster & 0.65 & $0.60-0.69$ & 0 & -0.21 & $-0.28--0.14$ & 0 & -0.11 & $-0.17--0.05$ & 0 & -0.03 & $-0.09-0.03$ & 0.33 & 486 \\
\hline \multicolumn{14}{|c|}{ \# Of Integrated Subjects Who Get Vaccine Before Trial Stopped, if Vaccine Unsafe or Not Immunogenic } \\
\hline 250 & 0.67 & $0.64-0.70$ & 0 & -0.2 & $-0.25--0.15$ & 0 & -0.02 & $-0.06-0.02$ & 0.35 & -0.02 & $-0.07-0.02$ & 0.31 & 992 \\
\hline 400 & 0.61 & $0.58-0.64$ & 0 & -0.24 & $-0.29--0.19$ & 0 & -0.04 & $-0.08-0.01$ & 0.09 & -0.05 & $-0.09--0.00$ & 0.05 & 943 \\
\hline 1,000 & 0.6 & $0.57-0.63$ & 0 & -0.27 & $-0.32--0.21$ & 0 & -0.09 & $-0.13--0.05$ & 0 & -0.09 & $-0.14--0.04$ & 0 & 997 \\
\hline
\end{tabular}

\section{Multivariate Regression Results}

Figure S5 also visualizes coefficients from a multivariate regression predicting preference for the integrated trial. Variables denoted with (Std.) have been rescaled to standard deviation 1. Note that these coefficients should be interpreted as descriptive, not causal, and that all coefficients are calculated holding constant the other variables shown. The intercept of the regression is 0.64 and the omitted base categories in the regressions are: United States; age 18-24; male; no college degree; employment one of homemaker, student, unable to work, or unemployed since before the coronavirus pandemic; the integrated trial being study A; and average values of the rescaled variables. The coefficients below represent estimated differences from these base categories, holding constant the other variables in the model.

Figure S6 shows the results of a multivariate regression regressing the same variables as above on a binary indicator for whether respondents got all the comprehension questions about the integrated study correct. Gender, age, views towards vaccines, and scientific knowledge generally predict comprehension. This regression was not pre-registered.

\section{Sensitivity Analysis}

We also conduct a sensitivity analysis to determine how unrepresentative our sample would need to be in order to alter our conclusions. In particular, we compute [5]'s $\gamma$ for the proportion that prefer the integrated study as 1.61 at a p-value of 0.10 . This means that our statistical significance for the null hypothesis that integrated trials are equally preferred to standard trials would only no longer reach significance at the 0.10 level were individuals who do not prefer integrated trials to be 1.61 times less likely than individuals who prefer integrated trials to be selected for the survey. For comparison, it is very unusual in social science studies to observe a $\gamma$ value greater than $2[4]$. 


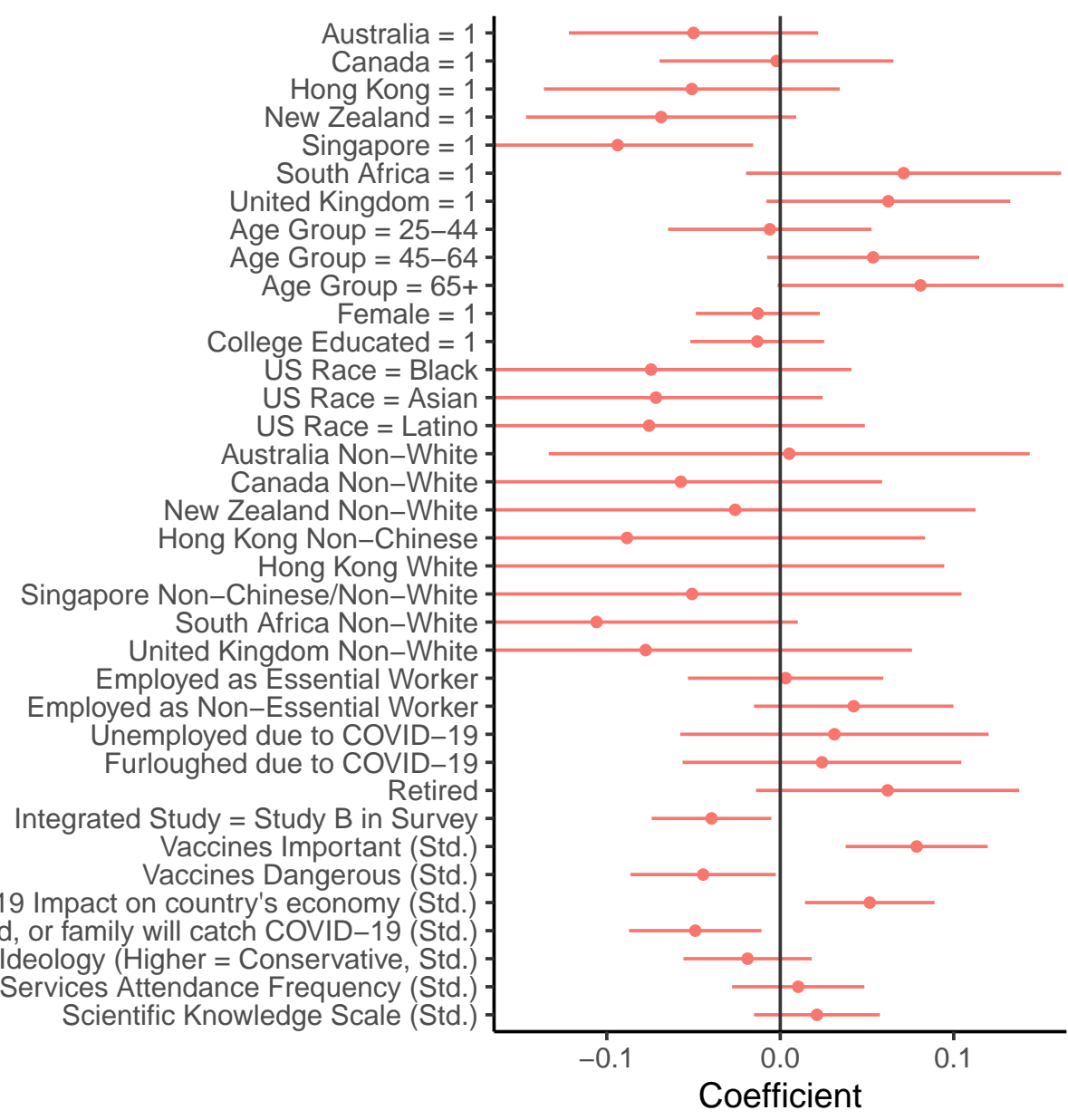

Figure S5: Predictors of Preference for Integrated Trial 


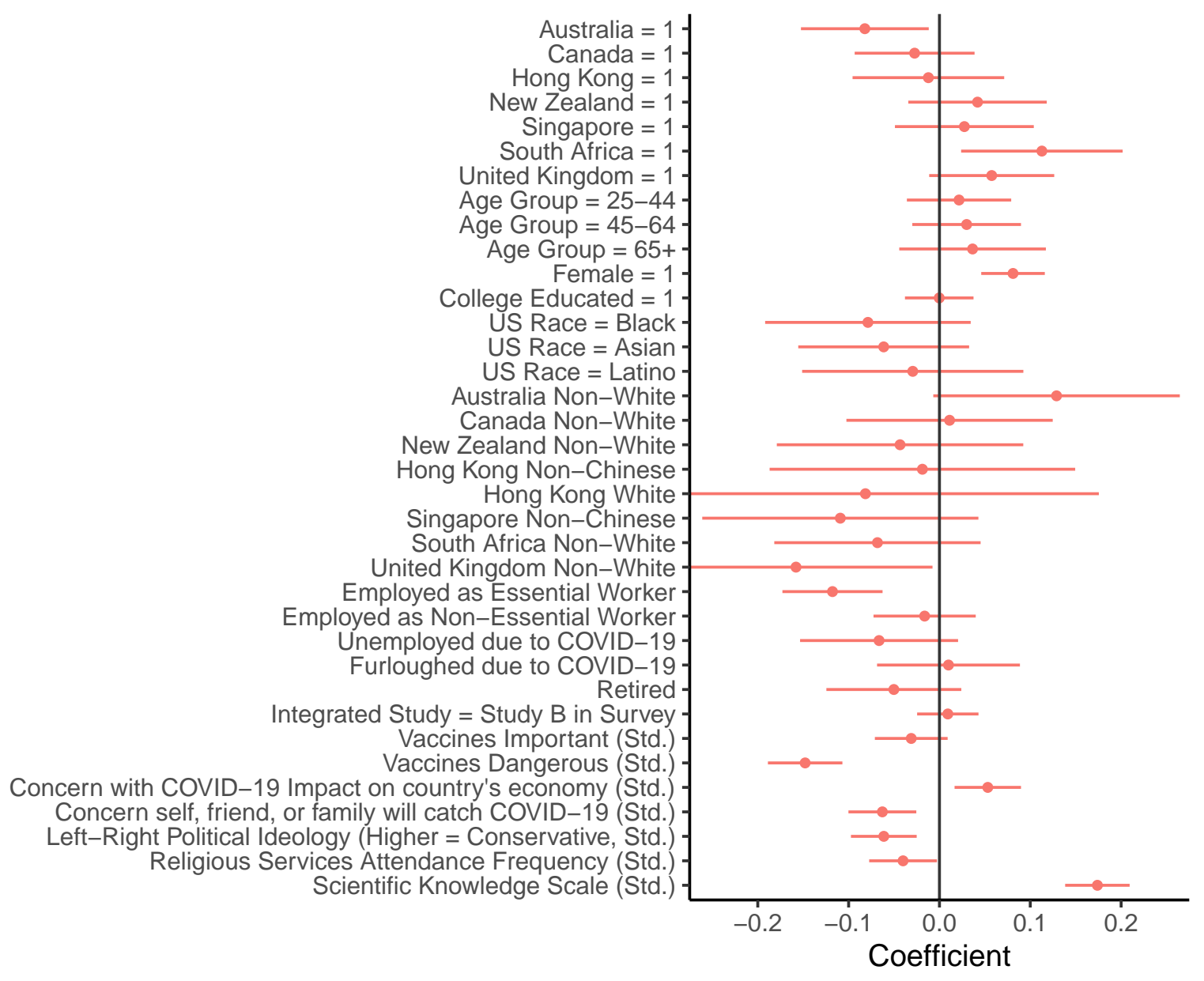

Figure S6: Predictors of Answering Scientific Knowledge Questions Correctly for Integrated Trial 


\section{Pre-Registration}

\section{Departures from Pre-Registration}

We made only minor departures from our pre-registered analysis in our pre-analysis plan:

- Given that participants to the survey were more likely to be college educated than the general population, we present results for "non-college educated" participants as a subgroup to show our results are robust among this group, which we had not pre-specified.

- There were an unanticipatedly large number of participants in Hong Kong who identified as white, and these participants gave distinctive responses to all the questions, affecting our average characterization of Hong Kong. The 2016 Hong Kong Census estimates that only $0.8 \%$ of the Hong Kong population identifies as white [1], so we report the results of self-identified non-white and white Hong Kong participants separately. As Tables S2 and S6 show, self-identified whites in Hong Kong were especially unlikely to understand the scenarios correctly, suggesting this group of self-identified white Hong Kong residents may have been a subset of participants in Hong Kong who were answering the survey carelessly, including the racial identification question itself. Consistent with this interpretation, the median self-identified white participant in Hong Kong spent only 95 seconds reading the main study table (we did not allow participants to move on from the page describing the trial design until at least 60 seconds had gone by), versus a median of 124 seconds in the rest of the Hong Kong sample and a median of 181 in the sample outside of Hong Kong.

\section{Pre-Registration Document}

Our pre-registration document appears on the following pages. It was filed prior to the collection of our survey data. 


\section{Pre-Registration and Pre-Analysis Plan: Public Perception of Ethical Trade-offs in COVID-19 Vaccine Trial Design}

We will be conducting an online survey to gauge how the public weighs various ethical trade-offs related to the design of vaccine trials. We will be conducting this survey in the United States, United Kingdom, Australia, Canada, New Zealand, Singapore, Hong Kong, and South Africa using the online survey provider Lucid. We aim for a sample size of 500 respondents per country and 2,000 in the United States. Respondents must take the survey on a desktop and be able to read English.

In the survey, we first ask two attention check questions. If respondents fail those attention checks, they are removed from the survey.

We then randomly assign respondents to one of two studies:

- Challenge Trial vs. Standard Design

- Integrated Phase 2/3 vs. Standard Design

In the Challenge Trial vs. Standard Design study, we randomize the following features:

- Standard Design Trial N (3,000; 5,000; 7,000; 9,000; 11,000)

- Challenge Trial N $(80 ; 100 ; 200)$

- $\%$ in Standard Design that are exposed to coronavirus in their daily lives $(2 \%, 5 \%, 20 \%)$

- $\%$ in Standard Design who die of coronavirus if they are exposed $(0.5 \%, 1 \%)$

- How long the Standard Design takes to get a vaccine ready: 12 or 18 months

- How much faster the Challenge Trial is: 2, 4, or 6 months faster

- Which design is described as "Study A" or "Study B"

In the Integrated Phase $2 / 3$ vs. Standard Design study, we randomize the following features:

- Standard Design Trial N (3,000; 5,000; 7,000; 9,000; 11,000)

- How long the Standard Design takes to get a vaccine ready: 12 or 18 months

- How much faster the Integrated Design is: 2, 4, or 6 months faster

- How many people in the Integrated Design are exposed to the vaccine before it stops, in the case that the vaccine is found to be unsafe $(250 ; 400 ; 1,000)$

- Which design is described as "Study A" or "Study B"

For each study, we will ask the following outcome measures:

- Primary outcome

If you had to choose, which study would you rather have scientists conduct? Study A; Study B

- This will be coded as 1 for Challenge/Integrated and 0 for Standard

- Secondary outcomes

○ How ethical do you think the studies are? Asked for both designs

- Definitely ethical (4); Probably ethical (3); Probably unethical (2); Definitely unethical (1) 
- We will analyze this outcome by taking the difference between Challenge/Integrated minus Standard

- We will also report the frequencies for the individual variables

- How scientifically valid do you think the studies are? Asked for both Study A and Study B

- Very valid (4); Somewhat valid (3); Somewhat invalid (2); Very invalid (1)

- We will analyze this outcome by taking the difference between Challenge/Integrated minus Standard

- We will also report the frequencies for the individual variables

- If the study found the vaccine worked and it was then approved by the government, how likely would you be to take the vaccine to protect yourself from coronavirus? Asked for both Study A and Study B

- Very likely (4); Somewhat likely (3); Somewhat unlikely (2); Very unlikely (1)

- We will analyze this outcome by taking the difference between Challenge/Integrated minus Standard

- We will also report the frequencies for the individual variables

For each study, we will also ask the following factual understanding questions to ensure respondents, on average, paid attention and understood the survey:

- If the vaccine works, which of the two studies we asked about would result in the vaccine being approved and widely available sooner?

- If the vaccine works, which of the two studies we asked about would result in more people in society generally dying of coronavirus?

- These questions will only be asked for the Challenge Trial vs. Standard Design study:

- Which of the two studies we asked about involves intentionally exposing participants to coronavirus while they are quarantined in a medical research center?

- Which of the two studies we asked about would result in more people in the study dying of coronavirus?

- Note: This question has a "Neither" option because in some randomizations, the number is the same.

- This question will only be asked for the Integrated vs. Standard Design study:

- Which of the two studies we asked about involves doing additional safety testing on a smaller group first?

- Each factual understanding variable will be recoded to have 1 for the correct answer and 0 for the incorrect answer based on the randomization.

We will conduct the below analyses for each study (challenge and integrated). For each average we describe below, we will perform a one-sample t-test, testing the null hypothesis that the challenge/integrated and standard designs are equal; this implies a null of 0.5 for the "If you had to choose" variable and a null of 0 for the secondary outcomes.

- Average value for each outcome, overall and by country

- Subgroups of primary interest are listed below. Our goal for subgroup analyses is to demonstrate the consistency of the findings across a) randomized descriptions of trial designs and b) salient 
social cleavages, especially among vulnerable populations and politically relevant groups. With this in mind, we will compute the average value and perform the t-tests mentioned above among participants in each of the subgroups mentioned below. We will only examine subgroups that are at least $\mathrm{N}=50$ in size.

- Demographic groups

- Only people 65 and over, given they are at highest risk for serious complications or death from coronavirus

- Only participants who understood all the factual understanding questions correctly

- Only participants who say they are "essential workers"

- Racial minorities. We will measure this as follows:

- US / UK / Australia / NZ / South Africa / Canada: those who do not select "White" to the race/ethnicity question

- Singapore and HK: Those who do not select "Chinese" to a race/ethnicity question

- Generally speaking, do you consider yourself

a...Democrat/Republican/Independent/Other Party. We will create indicators for each, pooling Independents and Other Party into one category. (This analysis will be done for US respondents only.)

- In a US county with cumulative COVID cases per capita above the median. To calculate COVID cases per capita, we will compute county population using 2019 Census population estimates (https://www2.census.gov/programs-surveys/popest/tables/2010-2019/counties/to tals/co-est2019-annres.xlsx) and COVID cases determined on the date of the launch of the survey, using the New York Times data at https://raw.githubusercontent.com/nytimes/covid-19-data/master/us-counties.csv. (This analysis will be done for US respondents only.)

- Randomized descriptions of trial designs

- By the number of months the Standard design takes and how much faster the Challenge/Integrated designs will be, as a $2 \times 3$ table with 6 separate statistics (reported separately for Integrated and Challenge)

- Average value for each outcome by the death rate and sick rate in the trial, as a $2 \times 3$ table with 6 separate statistics (Challenge only)

- Average value for each outcome by number of people who get the vaccine before it is determined to be unsafe (Integrated only)

- For each outcome, we will also report a regression to estimate which demographics predict support. We may also report raw means of outcomes within demographic categories. We will include the following predictors, all as linear predictors unless specified otherwise:

- In your opinion, how important is it that parents get their children vaccinated? Extremely important (5); Very important (4); Somewhat important (3); Not very important (2); Not at all important (1)

- Do you think vaccines are more dangerous than the diseases they are designed to prevent, or not? Yes (3); Unsure (2); No (1) 
- How concerned are you about the effect of the coronavirus on the country's economy? Very concerned (4); Somewhat concerned (3); Not very concerned (2); Not at all concerned (1)

- How concerned are you that you, someone in your family, or someone else you know will become infected with coronavirus? Very concerned (4); Somewhat concerned (3); Not very concerned (2); Not at all concerned (1)

- What is your year of birth? Recoded as age and groups into bins: $18-24 ; 25-44 ; 45-64$; $65+$, each analyzed as an indicator variable

- Which of the following best describes your gender? $1=$ female; $0=$ all other

- What is the highest level of education you have completed? 1 = college educated or above; $0=$ all other

○ In political matters, people talk of "the left" or "liberal" and "the right" or "conservative". How would you place your views on this scale, generally speaking? Coded from 1 (Liberal) to 10 (Conservative)

- What is your current employment status, and are you considered an "essential worker" during this pandemic? Indicators for employed as an essential worker; employed as a non-essential worker; unemployed due to COVID; furloughed due to COVID; and retired.

- Apart from weddings and funerals, about how often did you usually attend religious services last year? More than once a week (5); Once a week (4); Once a month (3); Only on special holy days (2); Once (1); Never (0)

○ Scientific knowledge. We ask respondents if they know "Which kind of waves is used to make and receive cellphone calls?" and "Ocean tides are created by which of the following?". Respondents get a 2 if they answer both correctly; a 1 if they answer one correctly; and a 0 if they answer none correctly

- An indicator for every country.

- Race/ethnicity: We will create indicators for US Black, US Asian, US Latino, and for non-white in each of the UK, Australia, NZ, South Africa, and Canada, and for non-Chinese in Singapore and Hong Kong.

- An indicator for whether the integrated/challenge study was randomized to be "Study A" or "Study B".

For a separate research question, we will also analyze the mean for the question examining preferences about a post-challenge trial safety study involving either 3,000 or 1 million people, both overall and among those $65+$ only. We may report both these results separately.

We may also conduct qualitative analyses of the open-ended responses to the questions asking respondents why they gave the answers about the ethics they did. Details of how we will conduct this analysis are not pre-registered.

Our primary analyses will be unweighted. As a robustness check, we will also present results for the United States using weights. For this analysis, we will weight to the ACS on age, gender, education, and 
race using the ebalance package in Stata. We will compute the weighted mean using the wtd.t.test function from the weights package in R. Our analysis will assume the weights are fixed. 


\section{References}

[1] Census and Statistics Department, Government of the Hong Kong Special Administrative Region of the People's Republic of China. Main tables, table a104. Available at https://www.bycensus2016.gov.hk/en/bcmt.html.

[2] Douglas R Green. Sars-cov2 vaccines: Slow is fast. Science Advances, 2020.

[3] Jens Hainmueller. Entropy balancing for causal effects: A multivariate reweighting method to produce balanced samples in observational studies. Political Analysis, 20(1):25-46, 2012.

[4] Luke Keele. An overview of rbounds: An r package for rosenbaum bounds sensitivity analysis with matched data. White Paper, 2010.

[5] Paul R Rosenbaum. Observational studies. 2020.

[6] Robert Verity, Lucy C Okell, Ilaria Dorigatti, Peter Winskill, Charles Whittaker, Natsuko Imai, Gina Cuomo-Dannenburg, Hayley Thompson, Patrick GT Walker, Han Fu, et al. Estimates of the severity of coronavirus disease 2019: a model-based analysis. The Lancet Infectious Diseases, 2020.

[7] World Health Organization. Key criteria for the ethical acceptability of covid-19 human challenge studies. Technical report, World Health Organization, 2020. 